\title{
Demand Side Management Potentials for Mitigating Energy Poverty in South Africa
}

\author{
Monyei, C. G. ${ }^{1,2,3}$ and Adewumi, A. O. ${ }^{1,2}$ \\ ${ }^{1}$ Applied Artificial Intelligence Research Unit, School of Mathematics, Statistics and \\ Computer Science, University of KwaZulu-Natal, Westville Campus, Private Bag X54001, \\ Durban 4000, South Africa \\ ${ }^{2}$ School of Mathematics, Statistics and Computer Science, University of KwaZulu-Natal, \\ Westville Campus, Private Bag X54001, Durban 4000, South Africa \\ ${ }^{3}$ Corresponding author \\ chiejinamonyei@gmail.com, adewumia@ukzn.ac.za
}

\begin{abstract}
South Africa is severally posited to be Africa's most industrialized nation with an economy heavily reliant on energy. With depleted electricity reserve margin which led to massive load shedding and rationing of electricity in 2008, Eskom has stepped up the construction of additional power plants to cover for growing supply deficits. Emerging trends however favour Demand Side Management (DSM) initiatives as alternatives to building additional supply capacity due to environmental and economic constraints. This research evaluates the electricity per capita for 2007, 2011 and 2016 on provincial basis assuming $100 \%$ and $36.8 \%$ residential sector consumption of generated electricity to show declining electricity per capita values. A scenario simulation (for $100 \%, 50 \%$ and $30 \%$ household participation) of cloth washers and cloth dryers optimal dispatch is then modelled to show the enormous DSM potentials in terms of electricity cost reduction and supply flexibility. A modified genetic algorithm (MGA) is used in the dispatch of participating loads on the Medupi power plant which has been modelled to operate with carbon capture and sequestration (CCS) technology. DSM potentials of $6938.34 M W, 3469.18 M W$ and $2081.51 M W$ are computed for $100 \%, 50 \%$ and $30 \%$ household participation for cloth washers and cloth dryers.
\end{abstract}

Keywords - energy poverty, electricity per capita, demand side management, scenario simulation, MGA

\section{Contents}

1 Introduction $\quad 2$

2 Background 4

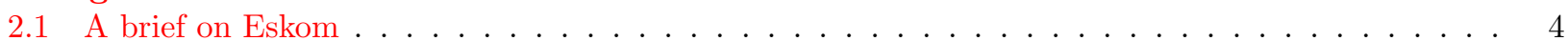

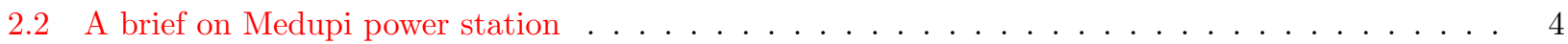

2.3 A brief on data utilized and sources . . . . . . . . . . . . . . . . . . . 4

3 Per capita electricity computation and its implications 5

3.1 Justification for tier classification . . . . . . . . . . . . . . . . . . . 6

4 The DSM optimisation process 6

4.1 Justification for choice of sectors for DSM application . . . . . . . . . . . . . . . . . 7

4.2 Electrical power load optimization and dispatch . . . . . . . . . . . . . . . . . 7

5 Modelling and scenario description $\quad \mathbf{7}$

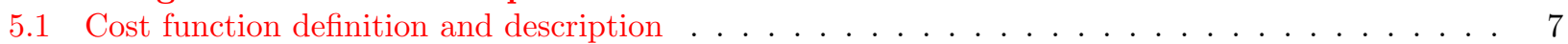

5.2 Dynamic price modelling . . . . . . . . . . . . . . . . . . . . . . 8

5.3 Time of use price modelling . . . . . . . . . . . . . . . . . . . . . 8

5.4 Optimization algorithm description . . . . . . . . . . . . . . . . . . 8 
6 Results and discussion $\mathbf{8}$

6.1 Policy discussion . . . . . . . . . . . . . . . . . . . . . . . . 9

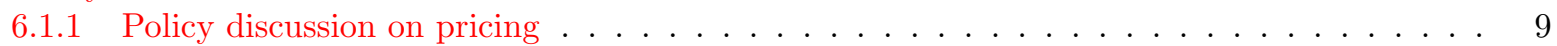

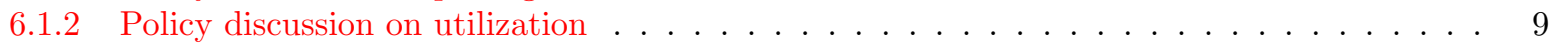

6.1 .3 Policy discussion on dispatch . . . . . . . . . . . . . . . . . . . . . . . . . . . . . . . . . . . . . . . .

6.1.4 Policy discussion on energy poverty mitigation . . . . . . . . . . . . . . . . . . . . . . . . . . . . . . . .

6.1.5 Policy discussion on supply capacity expansion . . . . . . . . . . . . . . . . . 10

7 Policy implementation and its challenges 10

8 Conclusion

9 Future research

10 Acknowledgement

Highlights
$\checkmark$ Presents declining electricity per capita across the provinces.
$\checkmark$ Evaluates DSM potential for dispatching cloth washers and cloth dryers.
$\checkmark$ Presents energy poverty mitigation ability of DSM application.
$\checkmark$ Discusses DSM policy arguments on pricing, load dispatch and power plant utilization.

\section{Introduction}

South Africa is one of Africa's most industrialized nation and also its highest net electricity producer (about $45 \%$ ) [19]. Most of the electricity consumed by the nine provinces of South Africa is produced by Eskom from 27 major power stations with combined installed nominal capacity of over 42000 MW from various sources including; coal, hydro, liquid fuel, pumped storage, nuclear and wind [67]. The significant growth witnessed in South Africa's electrification drive (rural and urban) which has seen electrification rate move rapidly from less than 33\% (in 1990) to 58\% (1996) and 90\% (2016) has been largely due to various government policy and intervention [44].

According to [44], electrification in South Africa which was around 35\% of the total population before 1990 had doubled by 2000. The 1996 census conducted revealed that about $58 \%$ of the countrys population had access to electricity. Continuing, [44] further posited that only about one in four non-urban black South African households were electrified compared to $97 \%$ electrification of non-urban white South African households before 1990. It could thus be surmised that the major obstacle to increased widening access to electricity was political, which kept electricity access prior to 1990 below 40\%. These dismal statistics highlighting low electrification rates for pre-1990 years were further worrisome when compared to countries with similar income levels at the beginning of the electrification program (Argentina 88\%, Venezuela 86\%, Costa Rica 85\%, Thailand $75 \%$ and Brazil 65\%). However, the abolishment of apartheid and subsequent entrenchment of democracy has led to a steady increase in electrification rates in the country. A further observation from the report [44] was the fact that as at 1990, South Africa had an extremely energy intensive economy and possessed in Eskom a world class electricity supply industry with a huge electricity reserve margin.

Table 1 [67] gives a breakdown of the contribution share of each energy source to Eskom's overall capacity while Table 2 [27] presents the time-line of the evolution of South Africa's power stations from 1926 to 2015 vis-a-vis their commissioning, decommissioning and recommissioning.

While government's initial efforts at boosting electricity generation and access led to a surplus in electricity supply in 1990 which resulted in the mothballing of the Komati, Camden and Grootvlei power stations, inconsistencies in government policies and an initial delay in the construction of additional power stations to compensate for increasing population and industrialization activities, have seen Eskom in recent times implementing load shedding $[40,42]$ to offset supply deficits and prevent grid collapse.

Government has consistently evolved policies to guarantee energy security and sufficiency right from the National Electrification Forum of 1991-1993. Furthermore, the South Africa Government electrification thrust is service delivery based rather than on providing energy for productive services. With an increasing population and rising demand of energy for both residential and non-residential (commercial, transportation, industrial etc.) activities, building additional power plants to boost supply though logical is becoming increasingly expensive as recognised in the United Kingdom by [8, 50]. In addition, global concerns relating to the negative contribution of fossil based electricity generation to the environment puts further constraints on the design and construction of these additional power plants. Further compounding South Africa's energy (electricity) sector drive issues is the fact that a number of South Africa's coal-powered plants will be decommissioned within the next decade. 
This presents a problem of energy security as planned replacements may not be able to completely cover the expected shortfalls due to delays in completion or other competing factors.

South Africa in keying into global trends has been increasing its energy base share of renewable energy. Interests has varied from solar (solar water heating) [25] to wind [24] to concentrating solar power (CSP) [20] etc. However, despite the modest contribution of renewable energy sources (RES) to South Africa's generation mix, their availability is both stochastic (with respect to location) and probabilistic (with respect to supply) which means that exactly quantifying their real time capacity via prediction does create some disparity between predicted and actual values. This is however at variance with generation from conventional sources like coal and diesel generator power plants whose capacities are known values and provide exact figures during system operations (SO) and planning.

Demand side management (DSM) has in recent times been gaining traction as a viable means of curtailing or modifying consumer's consumption pattern by shifting demand/supply imbalance control from the supply side to the demand (consumer) side. A reason for this is based on the fact that significant savings can be achieved from the consumer side that could eliminate the need for grid extension or additional generating capacity [45, 54]. In the United Kingdom for example, the Energy Efficiency Commitment Phases 1 and 2 (EEC1) and (EEC2) programmes which ran from 2002-2005 and 2005-2008 achieved energy savings of 86.8 TWh and 187 TWh respectively. Similarly, a carbon reduction of about $293 \mathrm{MtCO}$ was achieved via the Carbon Emissions Reduction Target (CERT) and Community Energy Saving Programme (CESP) between 2008-2012 [66]. In similar vein, Eskom in 2008 began a campaign to exchange incandescent bulbs in homes for more energy efficient CFL bulbs with about 65 million of such energy efficient CFL bulbs installed in South African homes to date. The result has been considerable energy savings and reduced electricity bills, job creation and a culture of greater energy efficiency among South Africans. It is estimated that about 11.8 TWh of DSM programs are currently in place in South Africa with expected cumulative savings of 466 MW by 2017/2018 from the additional Residential Mass Roll-out lighting LED program which commenced 2015/2016 [18].

In a recent report [57], it was posited that for South Africans to enjoy uninterrupted power supply, there had to be about a 10\% reduction in energy consumption (from the residential sector). It can therefore be evidenced and further inferred from the report that energy efficient habits (DSM) can guarantee a balance between electricity demand and supply for residential homes. However, statistics emanating from [16] indicate that national electricity demand using the less energy scenario modelling would increase (year-on-year) by $2.3 \%$ in 2016 and $2017,2.5 \%$ in 2018, 2.7\% in 2019 and $2.8 \%$ in 2020. To compensate for increasing electricity demand and diversify the generation mix, [17] posits that renewable energy planned capacity expansion is 2915 MW for 2016, 3799 MW for 2017, 4864 MW for 2018, 6879 MW for 2019 and 7867 MW for 2020. Furthermore, it is also observed from the IRP report [17] that capacity projections for DSM techniques remain at a low 500 MW for the short to medium term projections. More emphasis is however placed on new power stations with improved efficiency and lower carbon emissions which require huge investments in construction, operations and maintenance.

A review of available literature to our knowledge has revealed the absence of any research work that has effectively quantified in real terms the contribution of applying DSM on specific household electrical devices with available pricing techniques - time of use (TOU) and a proposed dynamic pricing (DP) regime with additional constraints of peaking limits and carbon emissions for South Africa. Research conducted during the write-up of this work further indicates that majority of existing literature target such areas as efficiency in industrial sectors, renewable energy, electricity intensity, policy, review and access. Table 3 highlights the focus areas of some selected scholarly works as regards South Africa's energy (electricity) sector. From Table 3, a hierarchy of the interests sees associated statistics and policy as the major centre of focus. For example, [6] evaluated the decision making process of consumers when purchasing energy efficient devices to determine if there was sync between the technology focus of consumers and current efficiency initiatives. The evaluation was carried out using a hierarchical decision model (HDM). Similarly, [2] applied bounds testing approach to cointegration with an autoregressive distributed lag framework to examine South Africa's electricity demand during the period 1960-2007 while [31] forecast electricity demand of South Africa up to 2030 using the Eagle-Granger methodology for co-integration and error correction models.

Works that touched on DSM include [12] where factors inhibiting municipalities from investing in DSM initiatives were investigated, [43] where a program for thermal efficiency in the South African residential sector was proposed and [55] where the authors described how an improved in line water heating concept could achieve peak load reduction without availability compromise within the specified operating time. Pricing and its effect on demand was also studied in [2] where the effect of pricing policy on aggregate demand and the magnitude of demand change/response to variation in pricing policy between 1960-2007 for South Africa was investigated. [32] also employed the Kalman filter in estimating the price elasticity of electricity in South Africa between 1980-2005.

According to [11], over $40 \%$ of global energy consumption comes from the residential and building sectors. This thus implies that households offer great potentials for DSM initiatives. This work therefore seeks to quantify in real terms the potential DSM capacity of cloth washers and cloth dryers for varying rate of household 
participation in South Africa. In this work, the Medupi power plant capacity is scaled between (arbitrarily selected) base loads and DSM loads. Simplified statistical derived equations are used in computing per capita electricity values for further discussions while a modified genetic algorithm (MGA) is used in allocating the evolved DSM loads (without optimizing dispatch) within the allocated DSM allowance to achieve pre-determined cost functions. The evaluated and simulated results are then used in extending policy discussions on pricing, power plant capacity utilization and load dispatch.

A motivation for this work stems from the fact that in utilizing dynamic pricing schemes, households can take advantage of lower electricity prices during off-peak periods to reduce electricity bills thus freeing up resources (money) for other purposes. Similarly, Eskom using direct load control (DLC) on participating demand response (DR) loads can minimize it's operations cost and ensure a smooth grid operation.

\section{Background}

In providing insight into declining electricity per capita across the years under consideration, associated statistics for South Africa relating to census (population, average household number, number of houses electrified and provincial electricity supply) would be utilized.

\subsection{A brief on Eskom}

Eskom is South Africa's major electricity provider, generating over 95\% of South Africa's electricity and $45 \%$ of Africa's electricity. Aside generation, Eskom also transmits and distributes electricity directly to the residential $(5.6 \%)$, mining $(14.4 \%)$, industrial $(22.3 \%)$, commercial and agricultural $(7 \%)$ and rail (1.4\%) sectors. International exports is about $5.6 \%$ while sale to municipalities is about $42.7 \%$. Production sources for its power generation varies from coal (83\%), nuclear (5\%), open-cycle gas turbine (OCGT, 3\%), independent power projects (IPPS, 3\%) to imports (4\%) [21]. Imports are from the Southern African Power Pool (SAPP) which is an inter-connected regional transmission network of the Southern African Development Community (SADC).

\subsection{A brief on Medupi power station}

Medupi power plant is a greenfield coal fired power plant project situated in the Limpopo province and is expected to be the fourth largest coal plant in the world. It has an installed capacity of 4764 MW from its six units each capable of outputting $794 \mathrm{MW}$. Unit 6 (the first of the 6 units) was synchronized with the grid in 2015. It has a planned operational lifetime of about 50 years [23, 22].

\subsection{A brief on data utilized and sources}

Data utilized for the computation of per capita electricity consumption was primarily sourced from Statistics South Africa (STATS SA). Population, average household size and number of electrified household per province were gotten from the 2007 community survey [13], 2011 census report [9] and the 2016 community survey [14]. Electricity supplied to each province was gotten from the P4141 series from STATS SA [64, 63].

Table 4 presents the population of South Africa's nine provinces from censuses conducted in 1996, 2001 and 2011 [9] and community surveys conducted in 2007 [13] and 2016 [14]. It is also observed from Table 4 the national percentage of homes with access to electricity and the growing trend in electricity access for the years under consideration. In trying to establish a justification for DSM, there is a need to present the declining electricity available to the residential sector by computing electricity per capita (yearly, monthly, daily and hourly). This is to provide insight into the prevailing energy poverty occasioned by increasing population and increasing demand for electrical power to meet consumer needs (heating/cooling, lighting, entertainment, cooking etc.).

Table 5 presents the electricity consumed by various sector and their ranking/position. It is observed from Table 5 that the residential sector consumes on average about $36.8 \%$ of total electricity supplied and comes second behind the industrial sector $(40.9 \%)$ [46].

Table 6 [64] further presents the supply of electricity to the nine provinces for three years (2007, 2011 and 2016) and the residential component of the electricity consumed for each province using the fraction (36.8\%) as obtained from Table 5. The provision of this additional column (residential component - YREC) is necessary in obtaining a more accurate value for per capita electricity consumption rather than a generalized value which assumes that $100 \%$ of electricity generated is consumed by the residential sector. Furthermore, the computation of the per capita values for electricity consumption also utilizes actual electrified households and the average household size for each province to obtain more accurate results. The method of computing electricity per capita thus employed in this research work is at variance with the generally established norm, as this employed method aims at showing the variation in electricity per capita across the different provinces. 
The number of households for years 2007, 2011 and 2016 for each province alongside the average household size and percentage of provincial households with access to electricity is presented in Table 7 [13, 9, 14].

\section{Per capita electricity computation and its implications}

The computation of the per capita electricity consumption for each of the nine provinces is shown subsequently. By per capita electricity consumption, we imply the average electricity consumption (Wh/kWh) computed for an individual (hourly, daily, monthly and yearly) based on the total electricity supplied to a province, number of electrified households and average household size. From Tables 5-7, the following can be obtained:

$n=$ Residential electricity component weight (0.368) from Table 5

$R E C_{j, k}=$ Residential electricity consumption for year $\mathrm{j}$ and province $\mathrm{k}$ from Table 6

$T E C_{j, k}=$ Total electricity consumption for year $\mathrm{j}$ and province $\mathrm{k}$ from Table 7

where,

$j$ is the index of year and $k$ is the index of the provinces. Equations (1) and (2) present the limits for $j$ and $k$ while Tables 8 and 9 present the index description for $j$ and $k$. That is,

$$
\begin{aligned}
& 1 \leq j \leq 3 \\
& 1 \leq k \leq 9
\end{aligned}
$$

If,

$\mathrm{THH}_{j, k}$ is the total households for year $\mathrm{j}$ and province $\mathrm{k}$ from Table 4

$A H H S_{j, k}$ is the average household size for year $\mathrm{j}$ and province $\mathrm{k}$ from Table 4 and

$H W E C_{j, k}$ is households with electricity connection for year $\mathrm{j}$ and province $\mathrm{k}$

Then,

$$
\begin{gathered}
H W E C_{j, k}=\frac{(\%) H W E C_{j, k}}{100}, \quad 0<H W E C_{j, k} \leq 1 \\
Y E C_{j, k}^{\eta=1}=\frac{T E C_{j, k}}{T H H_{j, k} \times A H H S_{j, k}}(k W h / \text { capita }) \\
M E C_{j, k}^{\eta=1}=\frac{Y E C_{j, k}^{\eta=1}}{12}(k W h / \text { capita }) \\
D E C_{j, k}^{\eta=1}=\frac{M E C_{j, k}^{\eta=1}}{30}(k W h / \text { capita }) \\
H E C_{j, k}^{\eta=1}=\frac{D E C_{j, k}^{\eta=1} \times 1000}{12}(\text { Wh/capita })
\end{gathered}
$$

where, $Y E C_{j, k}^{\eta=1}, \quad M E C_{j, k}^{\eta=1}, \quad D E C_{j, k}^{\eta=1}$ and $H E C_{j, k}^{\eta=1}$ are the yearly, monthly, daily and hourly provincial electricity consumption per capita (per individual) when all electricity supplied is assumed to be consumed by the residential sector $(\eta=1)$ and all households are assumed to be connected to the grid $\left(H W E C_{j, k}=1\right)$.

The result obtained from the computation of $Y E C_{j, k}^{\eta=1}, M E C_{j, k}^{\eta=1}, D E C_{j, k}^{\eta=1}$ and $H E C_{j, k}^{\eta=1}$ for the years 2007 , 2011 and 2016 for the nine provinces is shown in Table 10.

Similarly, the computation of the yearly $\left(Y E C_{j, k}^{\eta=0.368}\right)$, monthly $\left(M E C_{j, k}^{\eta=0.368}\right)$, daily $\left(D E C_{j, k}^{\eta=0.368}\right)$ and hourly $\left(H E C_{j, k}^{\eta=0.368}\right)$ provincial electricity consumption per capita when actual residential electricity consumed is taken into consideration $(\eta=0.368)$ with grid connected households $\left(H W E C_{j, k \neq 1}\right)$ is shown in equations $7-10$.

$$
\begin{gathered}
Y E C_{j, k}^{\eta=0.368}=\frac{T E C_{j, k}}{T H H_{j, k} \times A H H S_{j, k}}(k W h / \text { capita }) \\
M E C_{j, k}^{\eta=0.368}=\frac{Y E C_{j, k}^{\eta=0.368}}{12}(k W h / \text { capita }) \\
D E C_{j, k}^{\eta=0.368}=\frac{M E C_{j, k}^{\eta=0.368}}{30}(k W h / \text { capita }) \\
H E C_{j, k}^{\eta=0.368}=\frac{D E C_{j, k}^{\eta=0.368} \times 1000}{12}(\text { Wh/capita })
\end{gathered}
$$


Table 11 similar to Table 10 presents the results obtained from the computation of $Y E C_{j, k}^{\eta=0.368}, M E C_{j, k}^{\eta=0.368}$, $D E C_{j, k}^{\eta=0.368}$, and $H E C_{j, k}^{\eta=0.368}$ for the years 2007, 2011 and 2016 for the nine provinces.

Given $T E C_{j, k}$ as the total electricity supplied province $k$ for year $j$ in $G W h$, then $Y E C_{j, k}^{\eta=1}$ and $Y E C_{j, k}^{\eta=0.368}$ are the average yearly electricity $(k W h / c p i t a)$ consumed by an individual, with $100 \%$ and $36.8 \%$ consumption of electricity supplied province $k$ for $\eta=1$ and $\eta=0.368$ respectively by the residential sector. $M E C_{j, k}^{\eta=1}$ and $M E C_{j, k}^{\eta=0.368}$ are the average monthly electricity ( $k W h /$ capita) consumption per capita for $100 \%$ and $36.8 \%$ residential consumption of province $k$ supplied electricity. $H E C_{j, k}^{\eta=1}$ and $H E C_{j, k}^{\eta=0.368}$ are the average hourly electricity (Wh/capita) consumption per capita for province $k$.

A basis for the evaluation of the values presented in Tables 10 and 11 is to highlight the following:

(a) That while electricity access might have been increasing, electricity available for consumption by the residential sector has been decreasing rapidly across the years under consideration. For example, in Table 11, $H E C_{j, k}^{\eta=0.368}$ for Eastern Cape has declined from 72.42 Wh (in 2007) to 66.67 Wh (in 2011) and 63.39 Wh (in 2016). This trend is witnessed in all the provinces (except for Limpopo) for the years under consideration.

(b) That the evaluation of electricity consumption per capita for each province has shown the varying disparity among the provinces which is usually masked when electricity consumption per capita is computed for the whole nation. For example, from Table 11, while Mpumalanga has $H E C_{j, k}^{\eta=0.368}$ of 370.39 Wh in 2016, Eastern Cape has $H E C_{j, k}^{\eta=0.368}$ of about 63.39 Wh for 2016. An importance of this result is the fact that it affects the ownership of electrical appliances of residential houses which is useful in evaluating the Quality of Life (QoL) of household dwellers.

From Table 11 therefore, three classes (tiers) of residential consumers can be observed from the $H E C_{j, k}^{\eta=0.368}$ column in 2016. These are:

Tier 1: this tier consists of all residential consumers of electricity whose hourly consumption $H E C_{j, k}^{\eta=0.368}$ is less than $200 \mathrm{Wh}$, i.e. $0<H E C_{j, k}^{\eta=0.368}<200 \mathrm{Wh}$. It is observed from the Table 11 that in 2016, Eastern Cape, Limpopo, Western Cape, Free State and KwaZulu-Natal provinces were all tier 1 electricity consumers.

Tier 2: this tier consists of all residential electricity consumers with $200 W h \leq H E C_{j, k}^{\eta=0.368}<300 W h$. It is also observed from the Table 11 that in 2016 only Gauteng and Northern Cape residences was into this category.

Tier 3: this tier consists of residential users of electricity with $H E C_{j, k}^{\eta=0.368} \geq 300 W h$. North West and Mpumalanga residences were in this category as observed from the Table 11 in 2016.

\subsection{Justification for tier classification}

According to [48], there is a direct relationship between electrical appliance ownership and electrical consumption. In justifying the tier classifications (Tier 1, Tier 2 and Tier 3), Table 12 presents the ownership of electrical appliances by an individual used in meeting needs (lighting, entertainment, heating/cooling, and others). The classification of provincial residential houses into the various tiers is thus done to accurately depict the extent of ownership of electrical appliances by residences during the optimisation process of DSM.

The implication of the computed electricity per capita values for the provinces (when $\eta=0.368$ ) is best evaluated using scenario planning. Based on already adopted values of average house size per province, the typical electricity consumption per household is thus determined for each province. A fraction of the values determined are optimally allocated among competing DSM needs (cloth washers and cloth dryers) for a typical urban and typical rural house (both grid connected) with the ensuing statistics (cost and utilization) computed for both cases.

Table 13 presents a quick comparison between the yearly electricity per capita for the years under consideration as presented in the Tables 10 and 11 along with the World Bank value for 2007 and 2011 [30]. The disparity across the various scenarios raises doubts as to the viability of ensuing planning done using these values. Furthermore, the declining electricity per capita concerns earlier raised is further reinforced by [63]. According to [63], electricity consumption decreased by $1.2 \%$ and $1.5 \%$ in 2016 and 2015 respectively despite a $0.9 \%$ increase in electricity generation in 2016 over 2015.

\section{The DSM optimisation process}

In applying and optimising DSM, there is the need to justify its application. Figure 1 [60] presents the distribution of South AFrica's residential electricity usage among various competing needs. A sector ranking of Figure 1 shows that the Geyser, space heating, cold storage, others and the pool pump offer considerable potential for DSM application. However, DSM application is best suited for sectors that offer minimal discomfort to home owners and would not significantly impact negatively on the comfort level/QoL of home owners. Furthermore, the complexities involved in optimising user specific preferences for such complex sectors as cooling, heating etc. defeat the purpose for this research paper which is to show in simplest forms and without much significant 
investments the DSM potentials from residential homes. For this work therefore, two primary components of the laundry sector cloth washer and cloth dryer would be considered in the DSM optimisation process.

\subsection{Justification for choice of sectors for DSM application}

A justification for the choice of the laundry sector for DSM application and optimisation stems from the fact that the current DSM initiatives being undertaken by Eskom are efficiency based and not price-based. For example, Eskom has already initiated DSM for the lighting sector through the distribution of energy efficient bulbs across the country [18]. Furthermore, the laundry sector (cloth washer and cloth dryer) has also received significant appraisal in reviewed articles [39, 29, 62] due to its ability to have its functionality remotely monitored and controlled. Also, its operation can also be dispatched in real time without hitches. Additionally, data obtained shows that over $40 \%$ of South African homes have a washing machine [14], which cumulatively offers great potential for DSM.

Table 14 depicts the associated statistics (ratings and number) to be used in the optimisation process for both the cloth washer and the cloth dryer. For the purpose of this research, $60 \%$ of the $40 \%$ of residential homes with washing machine are assumed to have a cloth dryer. It is observed from Table 15 the possible periods of dispatch for the washing machine and cloth dryer for the week. Also observed is the fact that the washing machine and cloth dryer are capable of being dispatched all through the day. Hence, DSM would be optimally scheduling and dispatching the washing machines and cloth dryers within a 24-hour period to show the flexibility of its dispatch and also achieve the aim of the objective functions.

\subsection{Electrical power load optimization and dispatch}

An electricity network broadly consists of generation (supply) stations, transmission/distribution network and the utilization/consumers. At the supply/generation side, the aim of the supply side energy management system (SSEMS) is to minimize operations and emissions cost [28]. The transmission line management system (TLMS) ensures that line ampacity limits are not exceeded. Ampacity limits for transmission lines could be static or dynamic [15]. Home energy management systems (HEMS) aim at reducing the electricity bills of homes (while improving their comfort) by smartly dispatching loads during periods of low electricity cost [1]. The general grid operation thus aims at optimally scheduling generation and load dispatch to ensure demand-supply balance while meeting the individual objectives of SSEMS, TLMS and HEMS.

\section{$5 \quad$ Modelling and scenario description}

In providing a basis for policy arguments, the Medupi power plant is modelled as to utilize carbon capture and sequestration (CCS) technology and used in dispatching the combined washing machine and cloth dryer loads for a 24-hour cycle. Table 16 presents the DSM potentials for the three scenarios under consideration - 100\%, $50 \%$ and $30 \%$ household participation. Furthermore, $60 \%$ of households in all three cases are assumed to own a cloth dryer. The specific modelling properties of the Medupi power plant such as its operating range, emissions value and capacity are shown in Table 17.

Table 18 presents the distribution of DSM potentials among various dispatch time schedules. It is important to point out that the values have been stochastically evaluated based on the cumulative values presented in Table 16. This has been achieved by generating random values that cumulatively add up to the total number of houses in Table 16. For example, in Table 18, 100\% household participation for the cloth washer results in 1261518 houses for 15 mins. duration, 2207656 houses for 30 mins. duration, 946138 houses for 45 mins. duration and 1892277 houses for 60 mins. duration. The sum of the houses adds up to 6307589 (as shown in Table 16).

\subsection{Cost function definition and description}

In dispatching the evaluated loads based on their dispatch time, two cost functions - the utilization biased cost function $\left(U_{\text {bias }}^{\text {cost }}\right)$ and the consumer biased cost function $\left(C_{\text {bias }}^{\text {cost }}\right)$ are evaluated simultaneously. While $U_{\text {bias }}^{\text {cost }}$ aims at reducing the utilization cost which is the cost associated with operating the Medupi power plant outside its optimal operating limits as specified in Table 17, $C_{\text {bias }}^{\text {cost }}$ aims at reducing the associated cost of electricity to the consumers using dynamic pricing. The description of the cost functions are defined as:

$$
\begin{gathered}
U_{\text {bias }}^{\text {cost }}=\min \left(U_{\text {cost }}^{t}\right) \\
C_{\text {bias }}^{\text {cost }}=\min \left(D P_{\text {cost }}^{t}\right)
\end{gathered}
$$


Where,

$$
\begin{aligned}
& U_{\text {bias }}^{\text {cost }}= \begin{cases}0.2 \times O p_{t}^{\text {cost }} ; & \text { otherwise } \\
0 ; & G^{\text {norm }} \leq U t i l^{t} \leq G^{\text {max }}\end{cases} \\
& D P_{\text {cost }}^{t}=D P^{t} \times E_{M W h}^{t} \times 1000 \\
& O p_{t}^{\text {cost }}=a+\left(b \times \xi^{t}\right)
\end{aligned}
$$

$E_{M W h}^{t}$ is the real time/slot (t) energy to be utilized (MWh). $D P^{t}$ is the real time/slot dynamic price $(\mathrm{ZAR} / \mathrm{kWh}) .1000$ from equation (14) is the scaling factor for converting the price in (ZAR/kWh) to ZAR/MWh. $\xi^{t}$ is the loading factor is the fraction of the power plant currently being utilized (as a percentage). a and b are defined in Table 17. $G^{\text {norm }}$ and $G^{\max }$ are defined from Table 17 as the normal (norm) and maximum (max) operating capacity of the Medupi power plant respectively.

\subsection{Dynamic price modelling}

The computation of the dynamic price $D P^{t}$ follows the time of use (TOU) pricing being used by Eskom. As seen in Figure 2, the daily average dynamic price is equivalent to Eskom's spot price (excluding the peak periods). Given $F P^{t}$ as the real time TOU pricing electricity spot price, then $\frac{1}{24} \sum_{t=1}^{t=24}\left(D P^{t}\right)=\overline{F P^{t}}$

\subsection{Time of use price modelling}

The selected Eskom TOU pricing scheme is for a household whose monthly electricity consumption is less than $600 \mathrm{kWh}$. The cost for off-peak periods is about $Z A R 1.25 / \mathrm{kWh}$ and is exclusive of the peak period prices. For the purpose of this research, $20 \%$ has been added to the spot price during off-peak periods to generate the peak period (6am-8am and $6 \mathrm{pm}-8 \mathrm{pm})$ TOU price. Weekdays and weekend peak periods have been assumed to be similar. The generated pricing profile is also shown in Figure 2.

\subsection{Optimization algorithm description}

The first step involved modelling the behaviour of the Medupi power plant. MANN [47] was applied on data plot describing the evolution of the levelized cost of energy for various power plants [17] to generate constants $\mathrm{a}$ and $\mathrm{b}$ as shown in Table 17. The modified genetic algorithm (MGA) proposed and used in dispatching the loads to meet the already defined cost functions is described in Table 19. MGA is a variant of [47] and is modified to accommodate the variation in input data and optimization objective. The modifications introduced include: modifying the binary strings of the population matrix to generate integer numbers that determine the start time for dispatching load and constraining dispatch of cloth washers to precede cloth dryers. This is done by scaling the start time of cloth washers and cloth dryers. The modification of the binary bits is at variance with MIGA [47] where the binary bits are actual solutions. The cross-over employed is similar to [51] while the environmental cost was computed as shown in [41]. The prevailing exchange rate was gotten from [59].

\section{Results and discussion}

In dispatching the participating DSM loads, the Medupi power plant has its capacity (power) allocated between the base loads and the DSM loads. While the base power has been arbitrarily selected to match an actual scenario, the proposed MGA dispatches the DSM loads within the DSM allowance on the power plant. In achieving an optimal allocation that meets the cost functions, the MGA ensures that the plant capacity is not over-utilized. The values chosen for the base and DSM loads allowance are shown in Table 20 for the various household participation rate. The area plot shown in Figure 3(a) presents the 24-hour (96-slots) power dispatch for the cloth washers, cloth dryers and base load demand for 100\% participation of households. The real values for the cloth washer are gotten by deducting the base load value from the actual cloth washer value on the plot. Similarly, the real values for the cloth dryer are gotten by deducting the sum of the base load value and the corresponding cloth washer value (on the plot) from the actual cloth dryer value on the plot. While average utilization for both $C_{\text {bias }}^{\text {cost }}$ and $U_{\text {bias }}^{\text {cost }}$ is about $48 \%$, over-utilization of the power plant is not observed for both cases. The $C_{\text {bias }}^{\text {cost }}$ option achieves a daily savings of about ZAR 3,115 047 using dynamic pricing over the TOU pricing scheme for the same energy dispatch. This translates to about a $9.2 \%$ reduction in electricity cost using dynamic pricing over TOU pricing on average. The $U_{\text {bias }}^{\text {cost }}$ option dispatch shown in Figure 3(b) achieves a utilization cost of ZAR 5, 920 which is about $20 \%$ lower than the utilization cost obtained from the $C_{\text {bias }}^{c o s t}$ option.

The 24-hour (96-slots) power dispatch for the washing machines, cloth dryers and base load demand for a $50 \%$ participation of households is shown in the area plots depicted in Figure 4(a and b) for both cost functions. 
The computation of real values for the cloth washer and cloth dryer is similar to the description provided for reading Figure 3(a and b). Differing from the 100\% household participation, convergence of values is noticed between the $C_{\text {bias }}^{\text {cost }}$ and $U_{\text {bias }}^{\text {cost }}$ options. With a higher average plant utilization of $68.97 \%$, a $4.6 \%$ reduction in electricity cost for the participating households using dynamic pricing over TOU pricing is observed for both cost function options. The utilization cost for both cases is ZAR 23, 794.87.

Figure 5(a and b) presents the 24-hour dispatch of the power demand from the washing machine, cloth dryers and base loads for $30 \%$ household participation for both the $C_{\text {bias }}^{\text {cost }}$ and $U_{\text {bias }}^{\text {cost }}$ cost functions respectively. Similar to the $50 \%$ household participation, a convergence of the dispatch allocation for both cost functions is also observed. However, a higher average utilization of the power plant (81\%) is observed for both cost function options. Similar to the preceding household participation rates, electricity cost savings of about $5.1 \%$ by the dynamic pricing scheme over the TOU pricing scheme is further observed for both cost functions. The convergent utilization cost is about ZAR 29, 017.88. The computation of the real cloth washer and cloth dryer values is similar to the explanation provided in reading Figure 3 (a and b).

The savings accrued from $100 \%$ household participation translates to $247 \mathrm{Wh} /$ day per household. Similarly for $50 \%$ household participation it is $299 \mathrm{Wh} /$ day per household and $577 \mathrm{Wh} /$ day per household for $30 \%$ household participation. The implication of this is that the application of DSM is capable of extending the duration of comfort for $100 \%$ household participation by Tier 2 capacity. Similarly, 50\% household participation results in the comfort of participating households being extended by Tier 2 capacity while for $30 \%$ household participation, household comfort duration is extended by Tier 3 capacity. The relevance of this stems from the fact that the contribution of electrical appliances to comfort and QoL is not only a function of ownership but also of duration of usage. In mitigating poverty, the results obtained show that on average, households' monthly electricity bill (for DSM application on cloth washer and cloth dryer only) is reduced by $1.24 \%, 1.5 \%$ and $2.9 \%$ for $100 \%, 50 \%$ and $30 \%$ household participation respectively. This implies that resources could be freed up to consume more electricity for improved QoL.

\subsection{Policy discussion}

Table 21 presents corresponding daily values for $S_{\text {cost }}, P_{\text {cost }}^{D P}, P_{\text {cost }}^{F P}$ and $U_{\text {cost }}$ for $100 \%, 50 \%$ and $30 \%$ household participation and $C_{\text {bias }}^{\text {cost }}$ and $U_{\text {bias }}^{\text {cost }}$ cost functions. In presenting policy discussions, values would be used from Table 21 to highlight alternatives on pricing, utilization and dispatch of DSM loads for the residential sector (particularly washing machines and cloth dryers).

\subsubsection{Policy discussion on pricing}

According to [12], Eskom's distribution tariff does not always make local sense. This is because it penalises usage during peak periods. The consequence of this is that home owners are thus made to consciously reduce or totally avoid electricity consumption during these periods. Furthermore, this method is particularly worrisome to illiterate home owners who might have no clue as to the variation in electricity prices across the day. The proposed dynamic pricing scheme obviates the need for monitoring of price signals. With smart regulators attached to the washing machines and cloth dryers, all that home owners have to do is load their devices and indicate duration and turn over control to the utility. The utility updates its database to accommodate the new entrant and re-runs the proposed optimisation algorithm to obtain the optimal dispatch profile that meets the pre-determined cost objective. The benefits of incorporating the dynamic pricing scheme include the following:

(i) A possible reduction in household expenditure on electricity. As seen from Table 21, across all scenarios for $100 \%, 50 \%$ and $30 \%$ household participation, electricity cost is reduced using dynamic pricing over TOU pricing. According to $[10,38,52]$, there is a nexus between poverty and energy poverty which implies that a reduction in electricity bill for home owners frees up money that can be deployed for other activities capable of improving their QoL.

(ii) More flexibility in dispatch as the utility is able to more accurately optimise the grid and balance demand/supply. This is particularly useful in meeting grid constraints since the utility has more control over the entire electricity movement chain.

(iii) Optimization of electrical load dispatch to meet pre-determined constraints (reduced emissions, reduced electricity cost, reduced operational costs etc.).

\subsubsection{Policy discussion on utilization}

Spinning and supplemental reserves are important constituents in the electricity sector as they help in preventing grid collapse in the case of sudden upsurge in electricity demand. However, lack of participation of the electricity supplier in the demand sector could lead to over-compensation and large values of spinning/supplemental reserves leading to more operational losses for non-utilization of their capacity. The incorporation of DSM however provides the electricity supplier with more information which is useful in optimally sizing spinning/supplemental 
reserve capacities which leads to reduced operational costs. Furthermore, the incorporation of DSM as seen from Figures 3-5 helps in determining the optimal dispatch profile that could achieve the best average utilization of power plants. A critical observation of Table 21 shows a growing utilization cost despite increasing average utilization across the various household participation rate. This trend is due to a decreasing utilization of the allocated DSM capacity. The participation of the utility in influencing electricity end use could provide electricity demand data which can be used in optimally allocating DSM capacity for dispatch, thus freeing up more capacity for base loads.

\subsubsection{Policy discussion on dispatch}

A demerit of the application of Eskom's TOU pricing scheme is the fact that pseudo-peaks could be created during periods of cheaper electricity rates which is capable of disrupting the operation of the grid in case of demand exceeding supply capacity. A consequence of this has seen Eskom implementing load shedding to limit demand. Furthermore, dynamic pricing (especially when users are pre-informed of proposed spot prices) is capable of leading to pseudo-peaks [58]. The scheme being proposed here only assures home owners of a reduction in their electricity prices (for loads participating in DSM). This thus ensures that the utility is in control of the dispatch and is capable of managing demand surge. The dispatch of the DSM loads could be classified as:

(i) Without time constraint - here, the users do not specify any constraint as to when their loads should be dispatched. The decision of the time of dispatch is entirely left to the utility. However, an override function is provided to enable the home owners remove control from the utility at any time and dispatch their loads using the current TOU spot price. A penalty could also be included to the home owners electricity bill to reduce the repetition of such actions.

(ii) With time constraint - here, the users specify a window within which their loads should be dispatched. The pricing scheme here is more rigid since the utility is given a shorter time frame for flexibility.

\subsubsection{Policy discussion on energy poverty mitigation}

As earlier posited, energy poverty is related to ownership of electrical appliances [48]. However, monthly electricity bill is not just a function of ownership but duration of consumption. From Table 21, the application of dynamic pricing for $100 \%$ household participation results in a daily savings of about ZAR 3, 115, 047 over TOU pricing. This translates to about $2.5 \mathrm{GWh}$ at ZAR $1.25 / \mathrm{kWh}(247 \mathrm{Wh} /$ day per household). The savings accrued can be used for extended electricity consumption or other activities that contribute to improving the QoL of the household occupants. Similarly, for 50\% and 30\% household participation, dynamic pricing achieves daily savings of ZAR 1, 888, 028 and ZAR 2, 183, 429 over TOU pricing. This translates to extra daily power of $299 \mathrm{Wh}$ and $577 \mathrm{Wh}$ respectively per household. In terms of electricity cost reduction, dynamic pricing achieves $1.24 \%, 1.5 \%$ and $2.9 \%$ monthly reduction per household respectively.

\subsubsection{Policy discussion on supply capacity expansion}

According to [21], plant availability for the period under review was $74.4 \%$ with average utilization of $84.77 \%$. With a nominal installed capacity of $42000 \mathrm{MW}$, this translates to about $26500 \mathrm{MW}$ in terms of actual capacity utilization. According to [26], while $3516 \mathrm{MW}$ is expected to be lost due to the decommissioning of ageing plants between 2021 and 2024, over 19000 MW is expected to be added to the grid generation capacity between 2017 and 2024. This translates to a net increase of about $15484 \mathrm{MW}$. Furthermore, additional costs are expected to be spent in increasing the transmission capacity, on reactors, capacitors and transformers, to improve electricity supply. The expected addition to the grid capacity between 2017 and 2024 is over 5 times the capacity to be lost. Demand increase within 2017 and 2024 using the high (less energy intensive) forecast from [16] is about $55078 \mathrm{GWh}$. Assuming a $70 \%$ utilization (of net increase) at 35\% availability, this translates to a net production of about 131106 GWh between 2017 and 2024. The huge difference between demand and supply capacity is to ensure that system operators have a wide-margin of operation allowance to accommodate for sudden increase in demand or loss of generation unit. However, an advanced metering infrastructure (AMI) that supports DSM through direct load control (DLC), provides the utility with advanced information that can enable it efficiently schedule generator and load dispatch under constraints such as maintenance and outages. This thus ensures that enormous resources do not have to be spent in over-sizing generation capacity in anticipation of an increase in demand.

\section{$7 \quad$ Policy implementation and its challenges}

Considering the current grid structure, a scaled-up pilot study approach is advocated for implementation of proposed policy. In the scaled-up pilot study approach, a network of willing houses cutting across the three 
tiers within a distribution network is established. Specific devices within the houses are then fitted with the appropriate switches and controllers for communication with the household meter which communicates with the utility. On a micro-scale level, the utility is able to evaluate response of each tier members to real-time feedback on their consumption. This is in line with [37] where a 3.4\% reduction in energy consumption was reported for households that received feedback on their electricity consumption. Some of the challenges to the proposed policy implementation include cost (due to the current grid structure which is centralized and the technical requirements for implementing an AMI), manpower (considering the high technical expertise needed and the low technical skill shortage in South Africa [56]) and security/privacy concerns.

\section{Conclusion}

This research work has critically examined the electricity sector of South Africa and highlighted the fact that despite increasing investments in electricity generation, there is growing electricity poverty. Rather than taking the general approach in computing electricity per capita (assuming 100\% consumption of generated electricity and using national averages), per capita electricity consumption has been computed on provincial basis taking into consideration provincial electricity supply values, residential sector consumption rate, electrified houses and average household sizes on provincial basis. The results obtained are in contrast to the usually evaluated values and show the growing disparity in electricity per capita across the various provinces. Furthermore, DSM has been thoroughly investigated for cloth washers and cloth dryers only in South Africa assuming $100 \%, 50 \%$ and $30 \%$ household participation for two cost functions $\left(C_{\text {bias }}^{\text {cost }}\right.$ and $\left.U_{\text {bias }}^{\text {cost }}\right)$. A major reason for this research work is to show that DSM has a huge potential in mitigating energy (electricity) poverty in South Africa by reducing electricity cost and freeing up more money for either more electricity purchases or other activities that have the potential of improving their QoL. The results obtained show first that DSM potential of 6938.34 MW, 3469.18 MW and 2081.51 MW exits for 100\%, 50\% and 30\% household participation (for cloth washer and cloth dryers combined). Secondly, the application of DSM has been shown to mitigate poverty by reducing household electricity bills by $1.2 \%, 1.5 \%$ and $2.9 \%$ on monthly basis for $100 \%, 50 \%$ and $30 \%$ household participation. The savings accrued could then be utilized in activities that would contribute to the improvement of the household's QoL. In tackling energy poverty, the application of DSM on cloth washers and cloth dryers has shown that households' electricity consumption could be extended by $247 \mathrm{Wh} /$ day, $299 \mathrm{Wh} /$ day and $577 \mathrm{Wh} /$ day for $100 \%, 50 \%$ and $30 \%$ household participation. This implies that already owned electrical appliances can have extended usage on a daily basis as a result of lower electricity bills. The dispatch of the considered DSM loads has been carried out (using the Medupi Coal Power Plant which has been modelled to include CCS technology) to show that consumers electricity cost can be reduced using dynamic pricing when compared to the existing TOU pricing scheme used by Eskom. A modified genetic algorithm (MGA) has been designed specially for this research to optimally dispatch the participating households' loads based on the earlier highlighted cost objectives. Furthermore, this research has been able to show that the incorporation of DSM into grid operation beyond electricity cost reduction, offers the utility more control in managing the grid operation due to their increased control of electricity from generation to distribution. This becomes very useful during systems operations and planning as it ensures that the utility is capable of mitigating grid collapse and reducing operational and associated expenditure costs. Other DSM potential sectors that could be exploited include heating, ventilation and cooling (HVAC), dish washers etc.

\section{Future research}

Considering the results obtained from the computation of electricity per capita, future work would consider electricity per capita distribution among the various population groups (blacks, coloured, Indians/coloured) across the provinces to understudy the impact of Eskom's electrification thrust in ensuring equitable energy access across the various population groups. This would be important in formulating policy on electrification that would ensure energy access for all in line with the United Nations Sustainable Development Goals (UNSDGs) by 2030 .

\section{Acknowledgement}

The financial assistance of the National Research Foundation (NRF) and The World Academy of Sciences (TWAS) through the DST-NRF-TWAS doctoral fellowship towards this research is hereby acknowledged. Opinions expressed and conclusions arrived at, are those of the authors and are not necessarily to be attributed to the NRF. 


\section{References}

[1] S. Althaher, P. Mancarella, and J. Mutale. "Automated Demand Response From Home Energy Management System Under Dynamic Pricing and Power and Comfort Constraints". In: IEEE Transactions on Smart Grid 6.4 (2015), pp. 1874-1883.

[2] Hammed Amusa, Kafayat Amusa, and Ramos Mabugu. "Aggregate demand for electricity in South Africa: An analysis using the bounds testing approach to cointegration". In: Energy Policy 37.10 (2009), pp. 41674175. DOI: 10.1016/j.enpol.2009.05.016. URL: http://linkinghub.elsevier.com/retrieve/pii/ S0301421509003346.

[3] Chukwuma Leonard Azimoh et al. "Electricity for development: Mini-grid solution for rural electrification in South Africa". In: Energy Conversion and Management 110 (2016), pp. 268-277. DOI: 10 .1016/j . enconman.2015.12.015. URL: http://linkinghub.elsevier.com/retrieve/pii/S0196890415011152.

[4] Chukwuma Leonard Azimoh et al. "Illuminated but not electrified: An assessment of the impact of Solar Home System on rural households in South Africa". In: Applied Energy 155 (2015), pp. 354-364. DOI: 10.1016/j . apenergy . 2015 .05 . 120. URL: http: //linkinghub.elsevier . com/retrieve/pii / S030626191500759X.

[5] Bernard Bekker et al. "South Africa's rapid electrification programme: Policy, institutional, planning, financing and technical innovations". In: Energy Policy 36.8 (2008), pp. 3125-3137. DOI: $10.1016 / \mathrm{j}$. enpol.2008.04.014. URL: http://linkinghub.elsevier.com/retrieve/pii/S0301421508001961.

[6] Kevin C. van Blommestein and Tugrul U. Daim. "Residential energy efficient device adoption in South Africa". In: Sustainable Energy Technologies and Assessments 1 (2013), pp. 13-27. DOI: 10.1016/j . seta. 2012.12.001. URL: http://linkinghub.elsevier.com/retrieve/pii/S2213138812000033.

[7] Jessika Bohlmann et al. "An economy-wide evaluation of new power generation in South Africa: The case of Medupi and Kusile". In: Energy Policy 97 (2016), pp. 450-460. DOI: 10.1016/j . enpol.2016.07.020. URL: http://linkinghub.elsevier.com/retrieve/pii/S0301421516303731.

[8] Peter Bradley, Matthew Leach, and Jacopo Torriti. "A review of the costs and benefits of demand response for electricity in the UK". In: Energy Policy 52 (2013), pp. 312-327. DOI: http://doi .org/ 10.1016/j . enpol . 2012.09.039. URL: http:// www. sciencedirect. com/science/article/pii/ S0301421512008142.

[9] Census 2011 Provinces at a glance. [Online] Accessed: 2017-04-20. Pretoria, 2012. URL: http://www . statssa.gov . za/census / census_2011/census_products /Provinces $\% 20$ at $\% 20$ a $\% 20$ glance $\% 2016 \%$ 20 Nov $\% 202012 \% 20$ corrected.pdf.

[10] Shoibal Chakravarty and Massimo Tavoni. "Energy poverty alleviation and climate change mitigation: Is there a trade off?" In: Energy Economics 40, Supplement 1 (2013). Supplement Issue: Fifth Atlantic Workshop in Energy and Environmental Economics, S67 -S73. ISSN: 0140-9883. DOI: http://doi.org/ 10.1016/j . eneco.2013.09.022. URL: http:// www. sciencedirect.com/science/article/pii/ S014098831300217X.

[11] Fathia Chekired et al. "An Energy Flow Management Algorithm for a Photovoltaic Solar Home". In: Energy Procedia 111.Supplement C (2017). 8th International Conference on Sustainability in Energy and Buildings, SEB-16, 11-13 September 2016, Turin, Italy, pp. 934 -943. ISSN: 1876-6102. DOI: https: //doi .org/10.1016/j . egypro.2017.03.256. URL: http://www. sciencedirect.com/science/ article/pii/S1876610217302898.

[12] Alix Clark. "Demand-side management investment in South Africa: barriers and possible solutions for new power sector contexts". In: Energy for Sustainable Development 4.4 (2000), pp. 27-35. URL: http: //www.sciencedirect.com/science/article/pii/S0973082608602616.

[13] Community Survey 200\% [Online] Accessed: 2017-04-20. Pretoria, 2007. URL: http://www.statssa.gov . $\mathrm{za} /$ publications/Report-03-01-21/Report-03-01-212007.pdf.

[14] Community Survey 2016. [Online] Accessed: 2017-04-20. Pretoria, 2016. URL: http://cs2016. statssa. gov . za/wp-content/uploads / 2016/07/NT-30-06-2016-RELEASE-for-CS-2016-_Statisticalreleas_1-July-2016.pdf.

[15] Y. Cong et al. "On the Use of Dynamic Thermal-Line Ratings for Improving Operational Tripping Schemes"'. In: IEEE Transactions on Smart Grid 31.4 (2016), pp. 1891-1900.

[16] CSIR. Forecasts for electricity demand in South Africa (2014 2050) using the CSIR sectoral regression model. [Online] Accessed: 2017-04-20. 2016. URL: http : / /www . energy . gov . za/IRP/2016/IRPAnnexureB-Demand-forecasts-report.pdf. 
[17] DOE. Integrated Resource Plan Update - Assumptions, Base Case Results and Observations (revision 1). [Online] Accessed: 2017-04-20. 2016. URL: http: //www . energy . gov .za/IRP/2016/Draft-IRP-2016Assumptions-Base-Case-and-Observations-Revision1.pdf.

[18] Eskom. Compact fluorescent lamp rollout. [Online] Accessed: 2017-04-20. URL: http://www. eskom.co. $\mathrm{za/sites/idm/Residential/Pages/CFLRollout.aspx.}$

[19] Eskom. Company information overview. [Online] Accessed: 2017-04-20. URL: http://www.eskom.co.za/ OurCompany/CompanyInformation/Pages/Company_Information . aspx.

[20] Eskom. Concentrating Solar Power. [Online] Accessed: 2017-04-20. URL: http://www . eskom. co.za/ AboutElectricity / RenewableEnergy / ConcentratingSolarPower / Pages / Concentrating _ Solar _ Power_CSP. aspx.

[21] Eskom. Group Interim results for the six months ended 30 September 2015. Tech. rep. [Online] Accessed: 2017-09-15. Eskom, 2015. URL: http://www. eskom.co.za/IR2015/interim/Documents/Integrated_ results_presentation_30_Sep_2015_Final_20151124_POST_EXCO.pdf.

[22] Eskom. Medupi Power Station. Tech. rep. [Online] Accessed: 2017-09-15. Eskom, 2013. URL: http://www . eskom.co.za/Whatweredoing/NewBuild/MedupiPowerStation/Documents/BROCHUREmedupipowerstationproject. pdf.

[23] Eskom. Medupi produces its first power. Tech. rep. [Online] Accessed: 2017-09-15. Eskom, 2015. URL: http://www. eskom.co.za/news/Pages/MedupiSync.aspx.

[24] Eskom. Sere Wind Farm project. [Online] Accessed: 2017-04-20. URL: http : //www . eskom . co . za / AboutElectricity/RenewableEnergy/Pages/SereWindFarm.aspx.

[25] Eskom. Solar energy. [Online] Accessed: 2017-04-20. URL: http://www. eskom. co .za/IDM/EskomSolarWaterHeatingPr Pages/Solar_Water_Heating_Programme.aspx.

[26] Eskom. Transmission Development Plan 2016-2025. [Online] Accessed: 2017-05-18. URL: http://www . eskom.co.za/Whatweredoing/TransmissionDevelopmentPlan/Documents/TransDevPlan2016-2025Brochure. pdf.

[27] Eskom power stations from 1926 to 2015. [Online] Accessed: 2017-04-20. 2015. URL: https: //mybroadband. co.za/news/energy/122478-eskom-power-stations-from-1926-to-2015.html.

[28] J. Gunda and S. Djokic. "Coordinated control of generation and demand for improved management of security constraints". In: in proceedings of 2016 IEEE PES Innovative Smart Grid Technologies Conference Europe (ISGT-Europe). 2016, pp. 1-6.

[29] Seyed Mehdi Hakimi. "Multivariate stochastic modeling of washing machine loads profile in Iran". In: Sustainable Cities and Society 26 (2016), pp. 170 -185. ISSN: 2210-6707. DOI: http://doi.org/10.1016/j . scs.2016.06.004. URL: http://www. sciencedirect.com/science/article/pii/S2210670716301147.

[30] IEA. Electric power consumption (kWh per capita). [Online] Accessed: 2017-04-20. URL: http://data. worldbank . org/indicator/EG . USE. ELEC . KH . PC? end=2007\&locations=ZA\&start=2007\&view=bar\& year_low_desc $=$ false.

[31] Roula Inglesi. "Aggregate electricity demand in South Africa: Conditional forecasts to 2030". In: Applied Energy 87.1 (2010), pp. 197-204. DOI: 10.1016/j .apenergy .2009.08.017. URL: http://linkinghub. elsevier.com/retrieve/pii/S0306261909003493.

[32] R. Inglesi-Lotz. "The evolution of price elasticity of electricity demand in South Africa: A Kalman filter application". In: Energy Policy 39.6 (2011), pp. 3690-3696. DOI: 10.1016/j . enpol.2011.03.078. URL: http://linkinghub.elsevier.com/retrieve/pii/S0301421511002758.

[33] R. Inglesi-Lotz and J. N. Blignaut. "Electricity intensities of the OECD and South Africa: A comparison". In: Renewable and Sustainable Energy Reviews 16.7 (2012), pp. 4491-4499. DOI: 10.1016/j.rser. 2012. 04.004. URL: http://linkinghub.elsevier.com/retrieve/pii/S1364032112002614.

[34] R. Inglesi-Lotz and A. Pouris. "Energy efficiency in South Africa: A decomposition exercise". In: Energy 42.1 (2012), pp. 113-120. DOI: 10.1016/j.energy.2012.04.002. URL: http://linkinghub.elsevier . com/retrieve/pii/S0360544212002824.

[35] Roula Inglesi-Lotz and James N. Blignaut. "Improving the electricity efficiency in South Africa through a benchmark-and-trade system". In: Renewable and Sustainable Energy Reviews 30 (2014), pp. 833-840. DOI: 10 .1016/j .rser . 2013 .11.028. URL: http : / linkinghub . elsevier . com/retrieve/pii / S1364032113007776.

[36] Roula Inglesi-Lotz and James N. Blignaut. "South Africas electricity consumption: A sectoral decomposition analysis". In: Applied Energy 88.12 (2011), pp. 4779-4784. DOI: 10.1016/j . apenergy . 2011.06.018. URL: http://linkinghub.elsevier.com/retrieve/pii/S0306261911004065. 
[37] Yumiko Iwafune et al. "Energy-saving effect of automatic home energy report utilizing home energy management system data in Japan". In: Energy 125.Supplement C (2017), pp. 382 -392. ISSN: 0360-5442. DOI: https ://doi .org/10.1016/j . energy . 2017.02.136. URL: http://www . sciencedirect . com/ science/article/pii/S0360544217303195.

[38] Makoto Kanagawa and Toshihiko Nakata. "Analysis of the energy access improvement and its socioeconomic impacts in rural areas of developing countries". In: Ecological Economics 62.2 (2007). Special Section: Ecological-economic modelling for designing and evaluating biodiversity conservation policiesEE Modelling Special Section, pp. 319 -329. ISSN: 0921-8009. DOI: http://doi.org/10.1016/j . ecolecon. 2006.06.005. URL: http://www.sciencedirect.com/science/article/pii/S092180090600303X.

[39] E. Klaassen et al. "Evaluation of washing machine load potential for smart grid integration". In: Power Engineering Conference (UPEC), 2013 48th International Universities'. IEEE, 2013, pp. 1-6. DOI: 10 . 1109/UPEC. 2013.6714925.

[40] Marcel Kohler. "Differential electricity pricing and energy efficiency in South Africa". In: Energy 64 (2014), pp. 524-532. DOI: 10.1016/j.energy .2013.11.047. URL: http://linkinghub.elsevier .com/ retrieve/pii/S0360544213010177.

[41] E. T. Lau et al. "Optimization of carbon emissions in smart grids". In: 2014 49th International Universities Power Engineering Conference (UPEC). 2014, pp. 1-4. DOI: 10.1109/UPEC.2014.6934796.

[42] Loadshedding to run from 8am to 10pm today. [online] Accessed: 2017-05-01. URL: http://www.htxt.co. $\mathrm{za} / 2015 / 05 / 21 /$ loadshedding-to-run-from-8am-to-10pm-today/.

[43] C. Lombard, E. H. Mathews, and M. Kleingeld. "Demand-Side Management through thermal efficiency in South African houses". In: Energy and buildings 29.3 (1999), pp. 229-239. URL: http : //www . sciencedirect.com/science/article/pii/S0378778898000644.

[44] Andrew Marquard et al. South Africa's Electrification Programme an overview and assessment. 2007. URL: https://www.gsb.uct.ac.za/files/SAElectrificationworkingpaperfinal.pdf.

[45] Aditya Mishra et al. "Scaling Distributed Energy Storage for Grid Peak Reduction". In: 4th International Conference on Future Energy Systems. ACM, 2013, pp. 3-14.

[46] Daniel Modise and Vania Mahotas. South African Energy Sector. [Online] Accessed: 2017-04-20. URL: https : / / www . usea . org / sites / default / files / event - file / 497 / South_Africa_Country _ Presentation.pdf.

[47] Chukwuka G. Monyei, Aderemi O. Adewumi, and Michael O. Obolo. "Oil Well Characterization and Artificial Gas Lift Optimization Using Neural Networks Combined with Genetic Algorithm". In: Discrete Dynamics in Nature and Society 2014 (2014), pp. 1-10. DOI: http://dx.doi.org/10.1155/2014/289239.

[48] Chukwuka G. Monyei et al. "Nigeria's energy poverty: Insights and implications for smart policies and framework towards a smart Nigeria electricity network". In: Renewable and Sustainable Energy Reviews (2017). ISSN: 1364-0321. DOI: https://doi.org/10.1016/j.rser.2017.05.237. URL: http://www . sciencedirect.com/science/article/pii/S1364032117308882.

[49] Amandine Nakumuryango and Roula Inglesi-Lotz. "South Africas performance on renewable energy and its relative position against the OECD countries and the rest of Africa". In: Renewable and Sustainable Energy Reviews 56 (2016), pp. 999-1007. DOI: 10.1016/j.rser.2015.12.013. URL: http://linkinghub. elsevier.com/retrieve/pii/S1364032115013969.

[50] Ofgem. Making the electricity system more flexible and delivering the benefits for consumers. [Online] Accessed: 2017-04-20. London., 2015. URL: https://www . ofgem.gov.uk/ofgem-publications/96959/ flexibilitypositionpaperfinal-pdf.

[51] A.S.O. Ogunjuyigbe, C.G. Monyei, and T.R. Ayodele. "Price based demand side management: A persuasive smart energy management system for low/medium income earners". In: Sustainable Cities and Society 17 (2015), pp. 80 -94. ISSN: 2210-6707. DOI: http://doi.org/10.1016/j.scs.2015.04.004. URL: http://www.sciencedirect.com/science/article/pii/S221067071500044X.

[52] S. Pachauri et al. "On Measuring Energy Poverty in Indian Households". In: World Development 32.12 (2004), pp. 2083 -2104. ISSN: 0305-750X. DOI: http://doi.org/10.1016/j.worlddev. 2004.08.005. URL: http://www.sciencedirect.com/science/article/pii/S0305750X04001500.

[53] Marcio Giannini Pereira et al. "Evaluation of the impact of access to electricity: A comparative analysis of South Africa, China, India and Brazil". In: Renewable and Sustainable Energy Reviews 15.3 (2011), pp. 1427-1441. DOI: 10.1016/j .rser . 2010 .11 .005. URL: http://linkinghub . elsevier .com / retrieve/pii/S1364032110003746.

[54] J. Pierce and E. Paulos. "Beyond energy monitors: interaction, energy, and emerging energy systems". In: SIGCHI Conference on Human Factors in Computing Systems. ACM, 2012. 
[55] R. Rankin and P. G. Rousseau. "Demand side management in South Africa at industrial residence water heating systems using in line water heating methodology". In: Energy Conversion and Management 49.1 (2008), pp. 62-74. DOI: 10.1016/j.enconman.2007.05.022. URL: http://linkinghub.elsevier.com/ retrieve/pii/S0196890407001574.

[56] Vijay Reddy et al. SKILLS SUPPLY AND DEMAND IN SOUTH AFRICA. Tech. rep. LMIP Publication, Human Sciences Research Council, Pretoria., 2016.

[57] SA must reduce power by up to 15\%: Peters. [Online] Accessed: 2017-04-20. 2013. URL: https: //www . miningmx.com/news/energy/24324-sa-must-reduce-power-by-up-to-15-peters/.

[58] A. Safdarian, M. Fotuhi-Firuzabad, and M. Lehtonen. "A Distributed Algorithm for Managing Residential Demand Response in Smart Grids". In: IEEE Transactions on Industrial Informatics 10.4 (2014), pp. 2385-2393. ISSN: 1551-3203. DOI: 10.1109/TII.2014.2316639.

[59] SARB. SARB Exchange Rate. [Online] Accessed: 2017-04-24. URL: https://www.resbank.co.za/Pages/ default. aspx.

[60] Save electricity, we'll show you how: Eskom. [Online] Accessed: 2017-05-01. URL: https://businesstech. co.za/news/government/37768/save-electricity-well-show-you-how-eskom/.

[61] Ditiro Setlhaolo and Xiaohua Xia. "Combined residential demand side management strategies with coordination and economic analysis". In: International Journal of Electrical Power EG Energy Systems 79 (2016), pp. 150-160. DOI: 10.1016/j.ijepes.2016.01.016. URL: http://linkinghub.elsevier.com/ retrieve/pii/S014206151600017X.

[62] R. Shipman, M. Gillott, and E. Naghiyev. "SWITCH: Case Studies in the Demand Side Management of Washing Appliances". In: Energy Procedia 42 (2013). Mediterranean Green Energy Forum 2013: Proceedings of an International Conference MGEF-13, pp. 153 -162. ISSN: 1876-6102. DoI: http://doi .org/ 10.1016/j .egypro.2013.11.015. URL: http://www.sciencedirect.com/science/article/pii/ S1876610213017177.

[63] STATS-SA. Key findings: P4141 - Electricity generated and available for distribution, December 2016. [Online] Accessed: 2017-04-20. URL: http://www.statssa.gov.za/.

[64] STATS-SA. STATISTICAL RELEASE P4141 - Electricity generated and available for distribution. [Online] Accessed: 2017-03-20. URL: http://www.statssa.gov.za/.

[65] G. Thondhlana and H. W. Kua. "Promoting household energy conservation in low-income households through tailored interventions in Grahamstown, South Africa". In: Journal of Cleaner Production 131 (2016), pp. 327-340. DOI: 10.1016/j.jclepro.2016.05.026. URL: http://linkinghub.elsevier.com/ retrieve/pii/S0959652616304814.

[66] Peter Warren. "A review of demand-side management policy in the UK". In: Renewable and Sustainable Energy Reviews 29 (2014), pp. 941-951. DOI: http://doi.org/10.1016/j.rser. 2013.09.009. URL: http://www.sciencedirect.com/science/article/pii/S1364032113006680.

[67] Where Eskom's electricity comes from. [Online] Accessed: 2017-03-16. 2015. URL: https://mybroadband. co.za/news/energy/118671-where-eskoms-electricity-comes-from.html. 


\section{Nomenclature}

$A H H S_{j, k}$ year $j$, province $k$ average household size

$C_{\text {bias }}^{c o s t}$ consumer cost biased function

$C C S$ carbon capture and sequestration

$D E C_{j, k}^{\eta=0.368} / D E C_{j, k}^{\eta=1}$ Daily Electricity Consumption per capita (individual) for year $j$ assuming $36.8 \%$ and $100 \%$ respectively of electricity supplied province $k$ is consumed by the residential sector

$H E C_{j, k}^{\eta=0.368} / H E C_{j, k}^{\eta=1}$ Hourly Electricity Consumption per capita (individual) for year $j$ assuming $36.8 \%$ and $100 \%$ respectively of electricity supplied province $k$ is consumed by the residential sector

$H W E C_{j, k}$ Normalized value for province $k$ households with electricity connection for year $j$

$M E C_{j, k}^{\eta=0.368} / M E C_{j, k}^{\eta=1}$ Monthly Electricity Consumption per capita (individual) for year $j$ assuming $36.8 \%$ and $100 \%$ respectively of electricity supplied province $k$ is consumed by the residential sector

$O P_{t}^{\text {cost }}$ Time t operations cost

$P_{\text {cost }}^{D P} \quad$ Daily cost of electricity to consumers using dynamic pricing

$P_{\text {cost }}^{F P} \quad$ Daily cost of electricity to consumers using time of use pricing

$R E C_{j, k}$ Residential Electricity Consumption for province $k$, year $j$

$S_{\text {cost }}$ Daily operational cost of generating electricity by the utility

$T H H_{j, k}$ Total households for province $k$, year $j$

$U_{\text {bias }}^{\text {cost }}$ Utilization cost biased function

$U_{\text {cost }}$ Daily cost that penalizes generator utilization outside optimal operational limits

$Y E C_{j, k}^{\eta=0.368} / Y E C_{j, k}^{\eta=1}$ Yearly Electricity Consumption per capita (individual) for year $j$ assuming $36.8 \%$ and $100 \%$ respectively of electricity supplied province $k$ is consumed by the residential sector

DLC Direct Load Control

DSM Demand Side Management

MGA Modified Genetic Algorithm

QoL Quality of Life

TOU Time Of Use 


\section{List of Tables}

Table 1: Breakdown of energy category contribution to Eskoms capacity [67]

\begin{tabular}{lccc}
\hline Source/Category & Number & Capacity (MW) & \% of Eskom's total capacity \\
\hline Coal power & 13 & 34952 & 84.85 \\
Liquid fuel & 4 & 2409 & 5.85 \\
Nuclear power & 1 & 1830 & 4.44 \\
Pumped storage & 2 & 1400 & 3.40 \\
Hydro power & 6 & 600 & 1.46 \\
Wind power & 1 & 3 & 0.01 \\
\hline
\end{tabular}


Table 2: Timeline of power plants commissioning, recommissioning and decommissioning (1926 2015) [27]

\begin{tabular}{|c|c|c|c|c|c|}
\hline Power station & Power source & Commissioned & Decommissioned & Recommissioned & Status \\
\hline Witbank & Coal & 1926 & 1963 & & Not operational \\
\hline Colenso & Coal & 1926 & 1985 & & Not operational \\
\hline Salt River 1 & Coal & 1928 & 1979 & & Not operational \\
\hline Sabie River & Hydro & 1928 & 1964 & & Not operational \\
\hline Congella & Coal & 1928 & 1978 & & Not operational \\
\hline Klip & Coal & 1936 & 1986 & & Not operational \\
\hline Vaal & Coal & 1945 & 1989 & & Not operational \\
\hline Pretoria West() & Coal & 1952 & & & Operational \\
\hline Hex River & Coal & 1952 & 1988 & & Not operational \\
\hline Vierfontein & Coal & 1953 & 1990 & & Not operational \\
\hline Umgeni & Coal & 1954 & 1989 & & Not operational \\
\hline Taaios $(+)$ & Coal & 1954 & $1986 ; 1999$ & Yes & Not operational \\
\hline Wilge & Coal & 1954 & 1987 & & Not operational \\
\hline Salt River 2 & Coal & 1955 & 1994 & & Not operational \\
\hline West Bank 2 & Coal & 1956 & 1989 & & Not operational \\
\hline $\operatorname{Kelvin}(O)$ & Coal & 1957 & & & Operational \\
\hline Highveld $(+)$ & Coal & 1959 & $1986 ; 1999$ & Yes & Not operational \\
\hline $\operatorname{Komati}(+, E S)$ & Coal & 1961 & 1990 & Yes & Operational \\
\hline Ingagane & Coal & 1963 & 1990 & & Not operational \\
\hline Rooiwal() & Coal & 1963 & & & Operational \\
\hline $\operatorname{Camden}(+, E S)$ & Coal & 1967 & 1990 & Yes & Operational \\
\hline $\operatorname{Grootvlei}(+, E S)$ & Coal & 1969 & 1990 & Yes & Operational \\
\hline $\operatorname{Hendrina}(E S)$ & Coal & 1970 & & & Operational \\
\hline $\operatorname{Gariep}(E S)$ & Hydro & 1971 & & & Operational \\
\hline $\operatorname{Arnot}(E S)$ & Coal & 1975 & & & Operational \\
\hline $\operatorname{Kriel}(E S)$ & Coal & 1976 & & & Operational \\
\hline $\operatorname{Acacia}(E S)$ & Gas & 1976 & & & Operational \\
\hline Port $\operatorname{Rex}(E S)$ & Gas & 1976 & & & Operational \\
\hline Vanderkloof $\operatorname{Dam}(E S)$ & Hydro & 1977 & & & Operational \\
\hline $\operatorname{Duvha}(E S)$ & Coal & 1980 & & & Operational \\
\hline $\operatorname{Drakensberg}(E S)$ & Hydro & 1981 & & & Operational \\
\hline $\operatorname{Matla}(E S)$ & Coal & 1983 & & & Operational \\
\hline $\operatorname{Koeberg}(E S)$ & Nuclear & 1984 & & & Operational \\
\hline Lethabo $(E S)$ & Coal & 1985 & & & Operational \\
\hline Tutuka $(E S)$ & Coal & 1985 & & & Operational \\
\hline $\operatorname{Kendall}(E S)$ & Coal & 1988 & & & Operational \\
\hline $\operatorname{Palmiet}(E S)$ & Hydro & 1988 & & & Operational \\
\hline $\operatorname{Matimba}(E S)$ & Coal & 1993 & & & Operational \\
\hline $\operatorname{Majuba}(E S)$ & Coal & 1996 & & & Operational \\
\hline $\operatorname{Ankerlig}(E S)$ & Gas & 2007 & & & Operational \\
\hline $\operatorname{Gourikwa}(E S)$ & Gas & 2007 & & & Operational \\
\hline Newcastle(*) & Gas & 2007 & & & Operational \\
\hline $\operatorname{Medupi}(E S)$ & Coal & 2015 & & & Operational \\
\hline
\end{tabular}

$(O)$ - Aldwyeh International

$(+)$ - Mothballed

() - City of Tshwane

(*) - IPSA Group

$(E S)$ Eskom 
Table 3: Selected literature and their focus areas relating to South Africa's Energy (electricity) Sector

\begin{tabular}{lcc}
\hline Literature & Publication year & Focus area \\
\hline Blommestein and Daim, 20008[6] & 2013 & $\mathrm{~B}, \mathrm{D}, \mathrm{H}, \mathrm{I}$ \\
Amusa, Amusa and Mabugu, 2009[2] & 2009 & $\mathrm{D}, \mathrm{F}, \mathrm{I}, \mathrm{J}, \mathrm{K}$ \\
Azimoh et al, 2015[4] & 2015 & $\mathrm{~A}, \mathrm{C}, \mathrm{D}, \mathrm{I}, \mathrm{J}$ \\
Azimoh et al, 2016[3] & 2016 & $\mathrm{~A}, \mathrm{C}, \mathrm{D}, \mathrm{I}$ \\
Bekker et al, 2008[5] & 2008 & $\mathrm{~A}, \mathrm{D}, \mathrm{E}, \mathrm{F}$ \\
Bohlmann et al, 2016[7] & 2016 & $\mathrm{D}, \mathrm{F}, \mathrm{H}$ \\
Clark, 2000[12] & 2000 & $\mathrm{~B}, \mathrm{D}, \mathrm{F}, \mathrm{K}, \mathrm{J}$ \\
Inglesi, 2010[31] & 2010 & $\mathrm{~B}, \mathrm{D}, \mathrm{F}, \mathrm{H}, \mathrm{I}, \mathrm{J}, \mathrm{K}$ \\
Inglesi-Lotz and Blignaut, 2011[36] & 2011 & $\mathrm{D}, \mathrm{E}$ \\
Inglesi-Lotz, 2011[32] & 2011 & $\mathrm{D}, \mathrm{F}, \mathrm{H}, \mathrm{I}, \mathrm{K}$ \\
Inglesi-Lotz and Pouris, 2012[34] & 2012 & $\mathrm{~B}, \mathrm{D}, \mathrm{F}$ \\
Inglesi-Lotz and Blignaut, 2012[33] & 2012 & $\mathrm{~B}, \mathrm{D}, \mathrm{E}, \mathrm{F}$ \\
Inglesi-Lotz and Blignaut, 2014[35] & 2014 & $\mathrm{~B}, \mathrm{D}, \mathrm{E}, \mathrm{F}$ \\
Kohler, 2014[40] & 2014 & $\mathrm{~B}, \mathrm{D}, \mathrm{E}, \mathrm{F}, \mathrm{H}$ \\
Lombard, Mathews and Kleingeld, 1999[43] & 1999 & $\mathrm{~B}, \mathrm{~F}, \mathrm{I}$ \\
Nakumuryango and Inglesi-Lotz, 2016[49] & 2016 & $\mathrm{D}, \mathrm{E}$ \\
Pereira, 2011[53] & 2011 & $\mathrm{~A}, \mathrm{C}, \mathrm{D}, \mathrm{E}$ \\
Rankin and Rousseau, 2008[55] & 2008 & $\mathrm{~B}, \mathrm{C}$ \\
Setlhaolo and Xia, 2016[61] & 2016 & $\mathrm{~B}, \mathrm{C}, \mathrm{G}, \mathrm{I}, \mathrm{K}$ \\
Thondhlana and Kua, 2016[65] & 2016 & $\mathrm{~B}, \mathrm{~F}, \mathrm{I}$ \\
\hline
\end{tabular}

A - Electricity access; B - DSM; C - Quality of Life (QoL); D - Associated statistics

E - Review; F - Policy; G - Optimization; H - Modelling

I - Consumer side; J - Supply side; K - Pricing

Table 4: Provincial census/community survey population and national electricity access [13, 9, 14]

\begin{tabular}{lccccc}
\hline Province & 1996 & 2001 & 2007 & 2011 & 2016 \\
\hline Eastern Cape & 6147244 & 6278651 & 6527747 & 6562053 & 6996976 \\
Free State & 2633504 & 2706775 & 2773059 & 2745590 & 2834714 \\
Gauteng & 7834125 & 9388854 & 10451713 & 12272263 & 13399724 \\
KwaZulu-Natal & 8572302 & 9584129 & 10259230 & 10267300 & 11065240 \\
Limpopo & 4576566 & 4995462 & 5238286 & 5404868 & 5799090 \\
Mpumalanga & 3123869 & 3365554 & 3643435 & 4039939 & 4335964 \\
Northern cape & 1011864 & 991919 & 1058060 & 1145861 & 1193780 \\
North west & 2727223 & 2984098 & 3271948 & 3509953 & 3748436 \\
Western cape & 3956875 & 4524335 & 5278585 & 5822734 & 6279730 \\
Total & 40583572 & 44819777 & 48502063 & 51770561 & 55653654 \\
Household Electricity Access (\%) & 58.2 & 69.7 & 80.1 & 84.7 & 90.3
\end{tabular}

Table 5: Electricity usage/consumption by sector [46]

\begin{tabular}{lcc}
\hline Sector & Percentage of total consumption (\%) & Position/Ranking \\
\hline Residential & 36.8 & 2nd \\
Commercial & 11.4 & $3 \mathrm{rd}$ \\
Transport & 2.7 & $5 \mathrm{th}$ \\
Others & 8.1 & $4 \mathrm{th}$ \\
Industrial segment & 40.9 & $1 \mathrm{st}$ \\
\hline
\end{tabular}




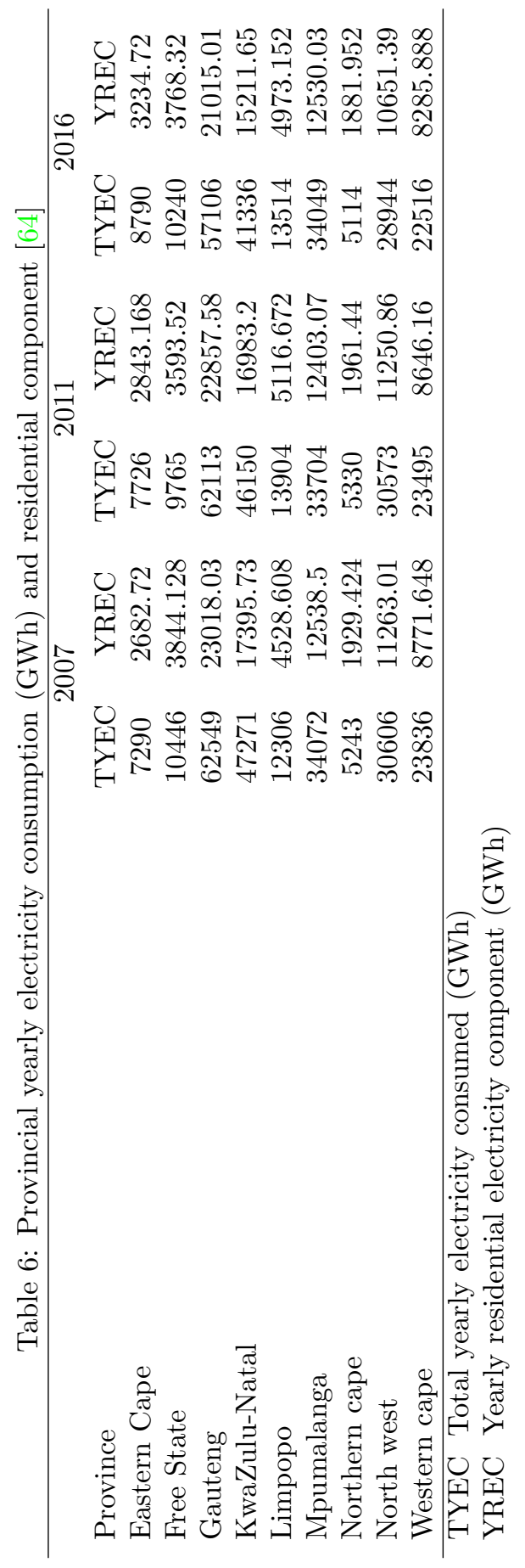




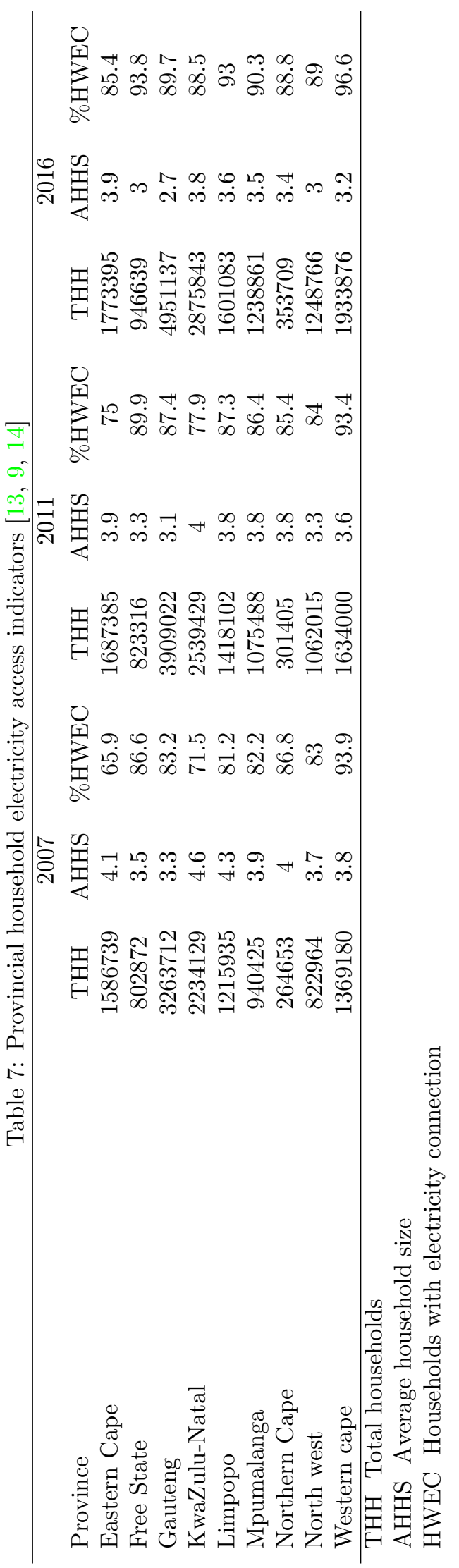


Table 8: Index description for $\mathrm{j}$

\begin{tabular}{cc}
\hline Year & Index $(\mathrm{j})$ \\
\hline 2007 & 1 \\
2011 & 2 \\
2016 & 3 \\
\hline
\end{tabular}

Table 9: Index description for $\mathrm{k}$

\begin{tabular}{lc}
\hline Province & Index $(\mathrm{k})$ \\
\hline Eastern Cape & 1 \\
Free State & 2 \\
Gauteng & 3 \\
KwaZulu-Natal & 4 \\
Limpopo & 5 \\
Mpumalanga & 6 \\
Northern cape & 7 \\
North west & 8 \\
Western cape & 9 \\
\hline
\end{tabular}




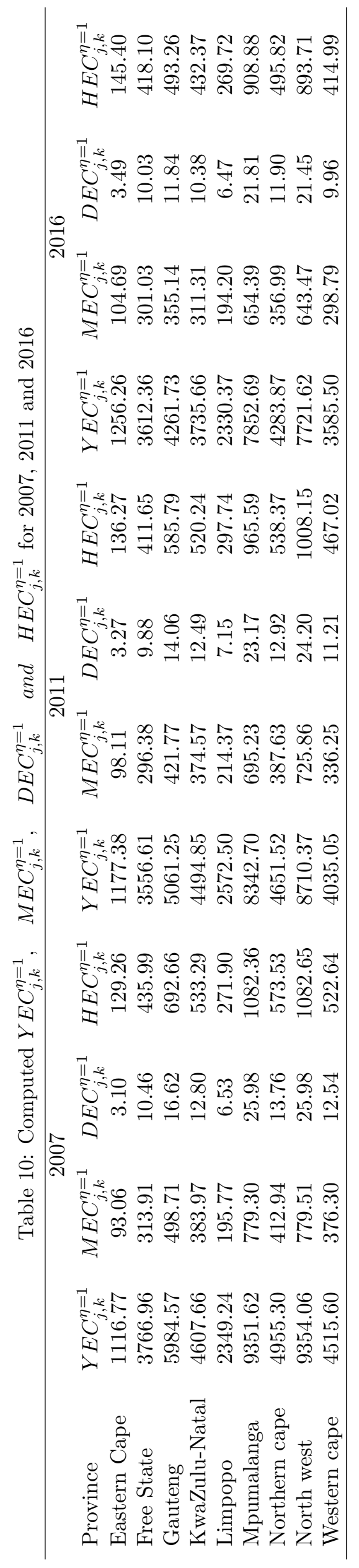




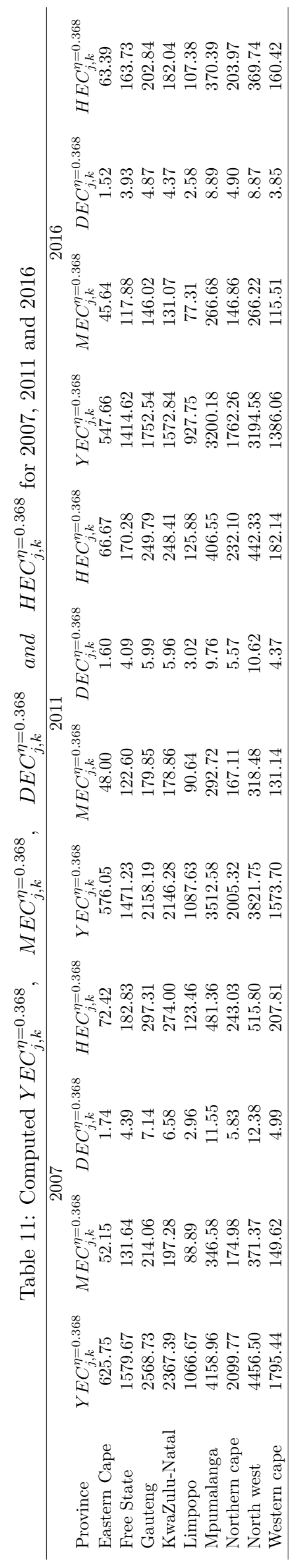


Table 12: Tier classification based on ownership

\begin{tabular}{|c|c|c|c|c|c|c|}
\hline \multirow[t]{2}{*}{ Needs } & \multirow[t]{2}{*}{ Devices } & \multicolumn{3}{|c|}{ Tier ownership } & \multirow{2}{*}{$\begin{array}{c}\text { Average Duration } \\
\text { (Hrs) }\end{array}$} & \multirow{2}{*}{$\begin{array}{c}\text { Unit rating } \\
(\mathrm{W})\end{array}$} \\
\hline & & 1 & 2 & 3 & & \\
\hline Lighting & Light bulb & 1 & 2 & $>2$ & 8 & 16 \\
\hline \multirow{3}{*}{ Entertainment } & TV & - & 1 & $\geq 1$ & 5 & 150 \\
\hline & Satellite decoder & - & 1 & 1 & 5 & 10 \\
\hline & VCD/DVD player & 1 & 1 & 1 & 5 & 35 \\
\hline \multirow[t]{2}{*}{ Heating/cooling } & Heater & - & $1^{*}$ & $\geq 1^{* *}$ & 8 & $1000 / 2000$ \\
\hline & $\mathrm{AC}$ & - & - & $\geq 1$ & $-{ }^{* * *}$ & $-* * *$ \\
\hline \multirow{4}{*}{ Others } & Dishwasher & - & - & 1 & 1 & 1200 \\
\hline & Cloth washer & - & - & 1 & 0.75 & 500 \\
\hline & Cloth dryer & - & - & 1 & 1 & 700 \\
\hline & Cooker & - & - & 1 & 2.5 & $750 / 1500$ \\
\hline
\end{tabular}

$*-\leq 1000 \mathrm{~W} \quad * *->1000 \mathrm{~W} \quad * * *-$ not evaluated since summer season is assumed.

AC - Air conditioner TV - Television

All values used are assumed for justification of Tier classification.

Table 13: Electricity per capita comparison for selected years

\begin{tabular}{cccc}
\hline Year & World Bank [30] & $\eta=1$ & $\eta=0.368$ \\
\hline 2007 & 4875.108 & 5111.308 & 2302.098 \\
2011 & 4590.547 & 4733.581 & 2039.192 \\
2016 & - & 4293.34 & 1750.944 \\
\hline
\end{tabular}

Table 14: Washing machine and cloth dryer statistics

\begin{tabular}{lccc}
\hline Equipment & Device Rating (W) & Number per household & Total Power (W) \\
\hline Washing machine & 500 & 1 & 500 \\
Cloth dryer & 1000 & 1 & 1000 \\
\hline
\end{tabular}

Table 15: Weekday dispatch of proposed DSM loads

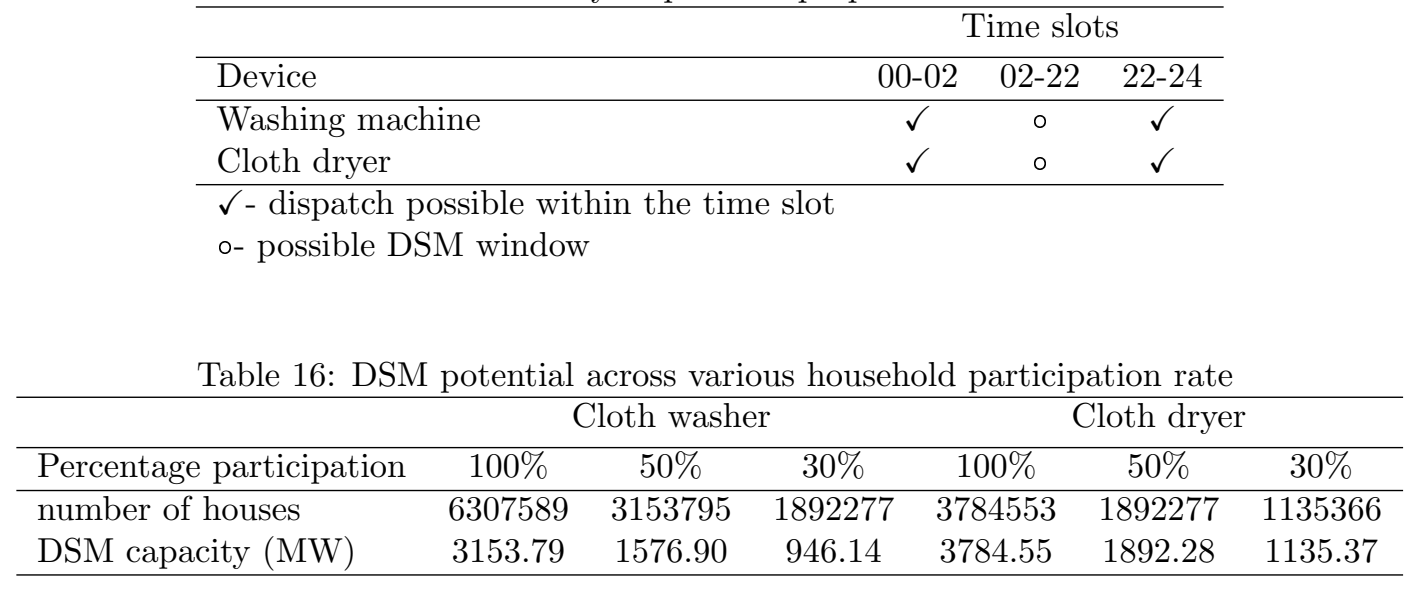

Table 17: Modified Medupi Power Plant Modelling Parameters

\begin{tabular}{lcccccccc}
\hline & \multicolumn{2}{c}{ LCOE model values } & \multicolumn{2}{c}{ Operating range (\%) } & Carbon emissions & Capacity \\
\hline Technology & $\mathrm{a}$ & $\mathrm{b}$ & $\min$ & $\max$ & norm & & $(\mathrm{kg} / \mathrm{MWh})$ & $(\mathrm{MW})$ \\
\hline CCS & 2815.21 & -14.80 & 66 & 88 & 85 & & 136.2 & 1588 \\
\hline LCOE - Levelized cost of energy & & & & & & & &
\end{tabular}

CCS - Carbon capture and sequestration

Table 18: DSM household potential across various time schedules

\begin{tabular}{ccccccc}
\hline & \multicolumn{3}{c}{ Cloth washer } & \multicolumn{3}{c}{ Cloth dryer } \\
\hline & $100 \%$ & $50 \%$ & $30 \%$ & $100 \%$ & $50 \%$ & $30 \%$ \\
\hline 15 mins & 1261518 & 441531 & 908293 & 378455 & 321687 & 90829 \\
$30 \mathrm{mins}$ & 2207656 & 851525 & 189228 & 2081504 & 473069 & 681220 \\
$45 \mathrm{mins}$ & 946138 & 883062 & 321687 & 1173211 & 870447 & 317902 \\
$60 \mathrm{mins}$ & 1892277 & 977676 & 473069 & 151382 & 227073 & 45415 \\
\hline
\end{tabular}


Table 19: Modified Genetic Algorithm Description

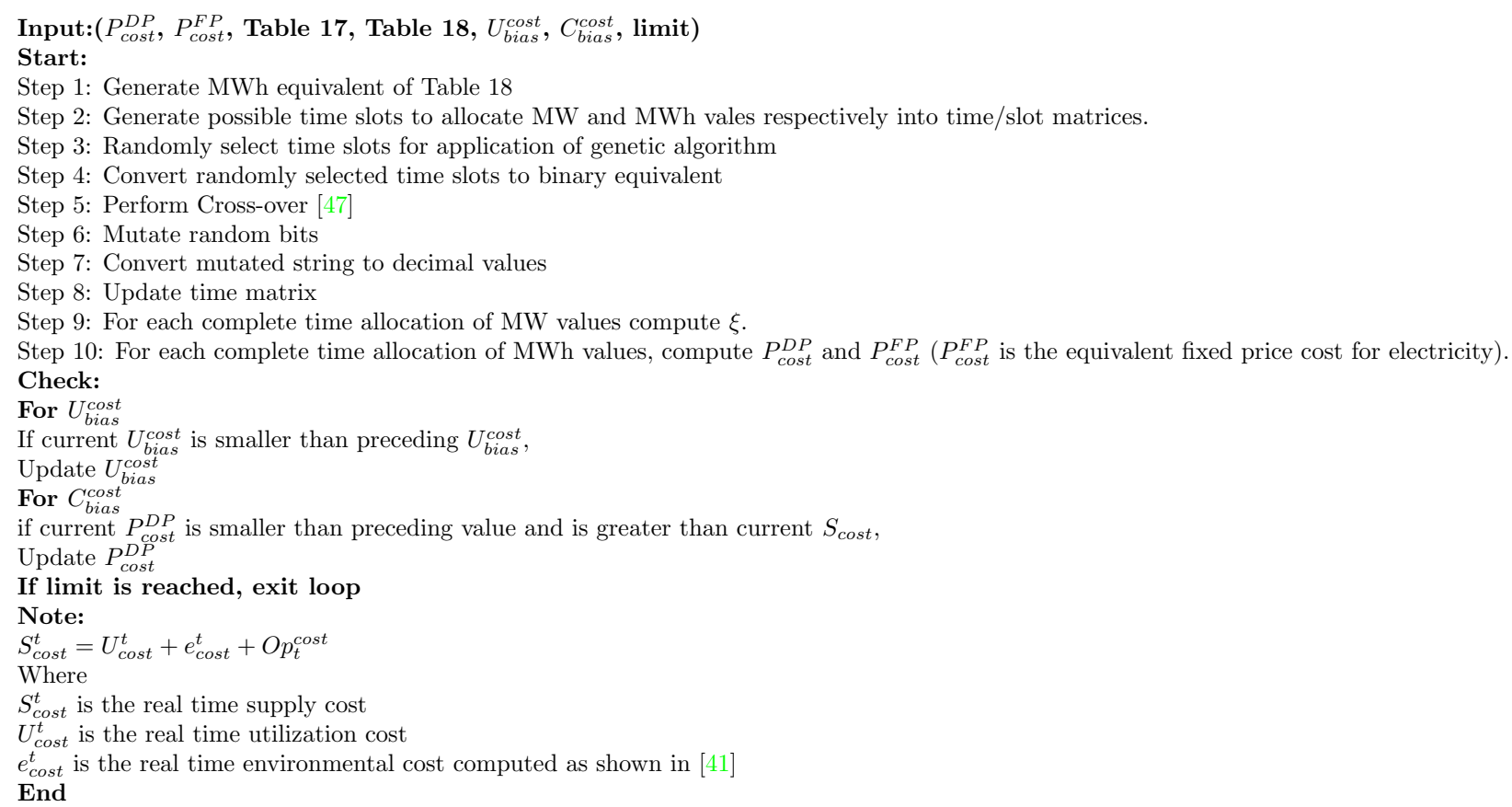

Table 20: Power allocation for base and DSM loads

\begin{tabular}{ccc}
\hline Household participation (\%) & Base load allowance (MW) & DSM allowance (MW) \\
\hline 100 & 588 & 1000 \\
50 & 1000 & 588 \\
30 & 1238 & 350 \\
\hline
\end{tabular}

Table 21: Associated dispatch values for $C_{\text {bias }}^{\text {cost }}$ and $U_{\text {bias }}^{\text {cost }}$ options

\begin{tabular}{lcccccc}
\hline household participation & \multicolumn{2}{c}{$100 \%$} & \multicolumn{2}{c}{$50 \%$} & \multicolumn{2}{c}{$30 \%$} \\
Cost function & $C_{\text {bias }}^{\text {cost }}$ & $U_{\text {bias }}^{\text {cost }}$ & $C_{\text {bias }}^{\text {cost }}$ & $U_{\text {bias }}^{\text {cost }}$ & $C_{\text {bias }}^{\text {cost }}$ & $U_{\text {bias }}^{\text {cost }}$ \\
\hline$S_{\text {cost }}$ & 8442025 & 8434699 & 10239392 & 10239392 & 10922049 & 10922049 \\
$P_{\text {cost }}^{F P}$ & 33869750 & 33708250 & 40397500 & 40397500 & 43007000 & 43007000 \\
$P_{\text {cost }}^{D P}$ & 30754703 & 34951081 & 38509472 & 38509472 & 40823571 & 40823571 \\
$U_{\text {cost }}$ & 7390.13 & 5920 & 23794.87 & 23794.87 & 29017.88 & 29017.88 \\
\hline
\end{tabular}




\section{List of Figures}

\section{\% Composition of Total Energy Consumption}

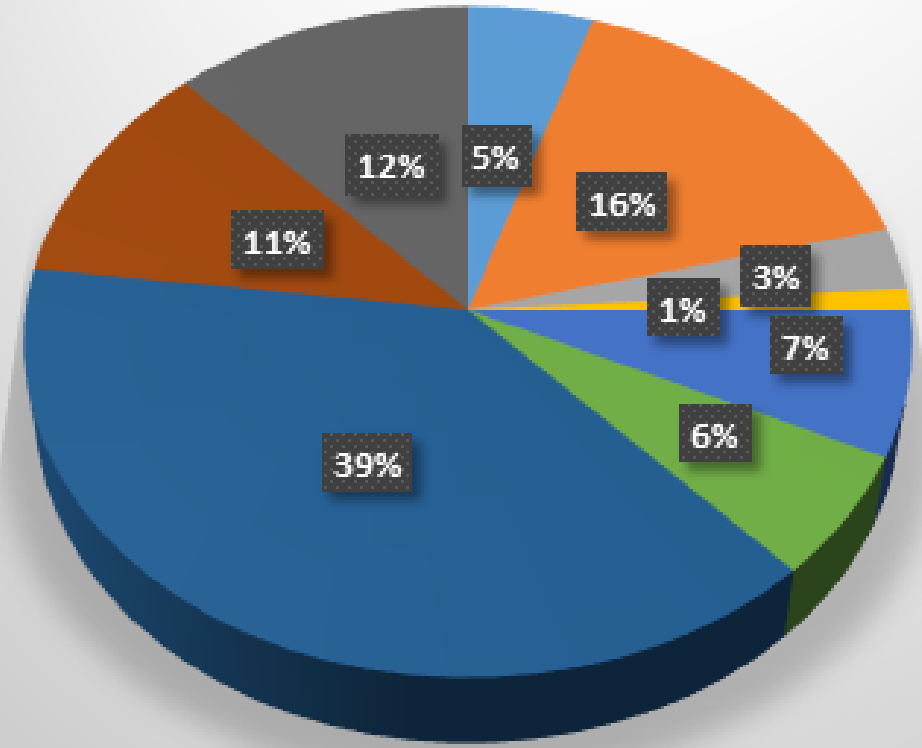

ncold storage

= Space heating

naundry

= Other cooking

-Stove/Oven

- Lights

-Geyser

- Pool pump

nothers

Figure 1: Residential home electricity usage distribution among various needs [60]. 


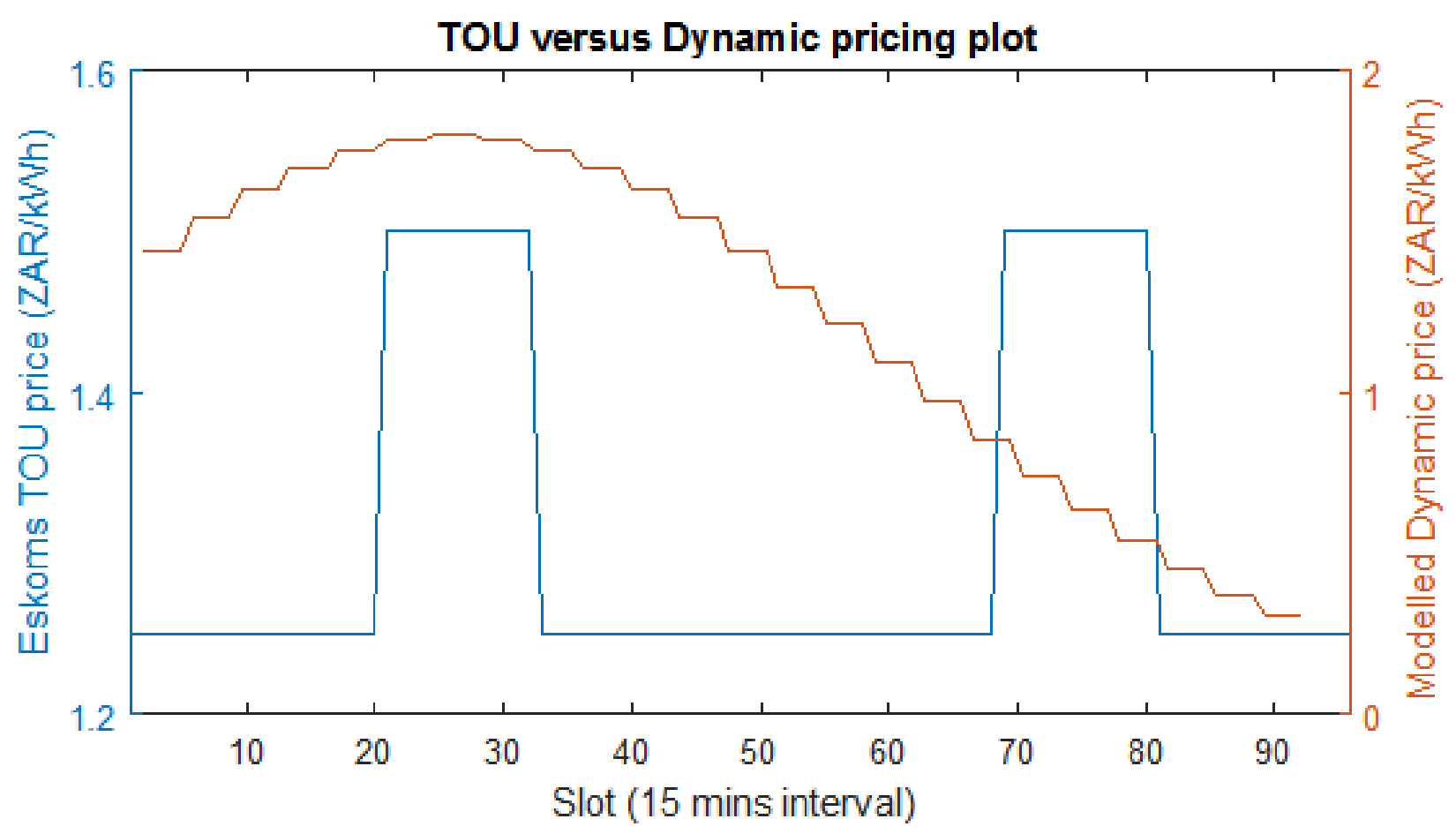

Figure 2: TOU pricing and dynamic pricing profiles.

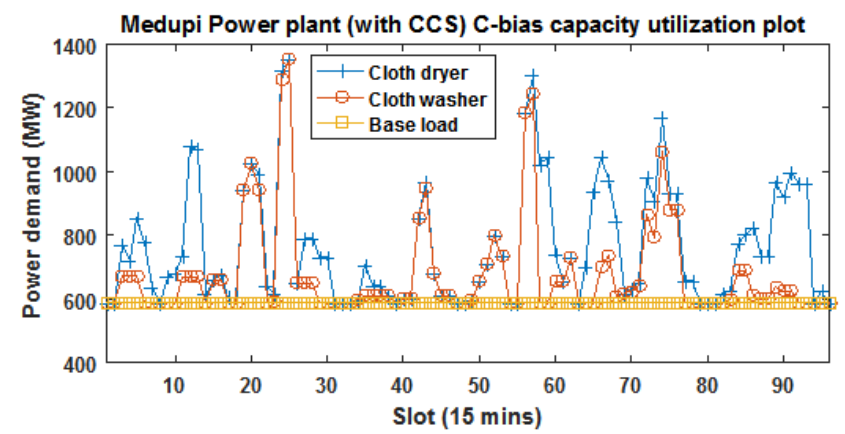

(a)

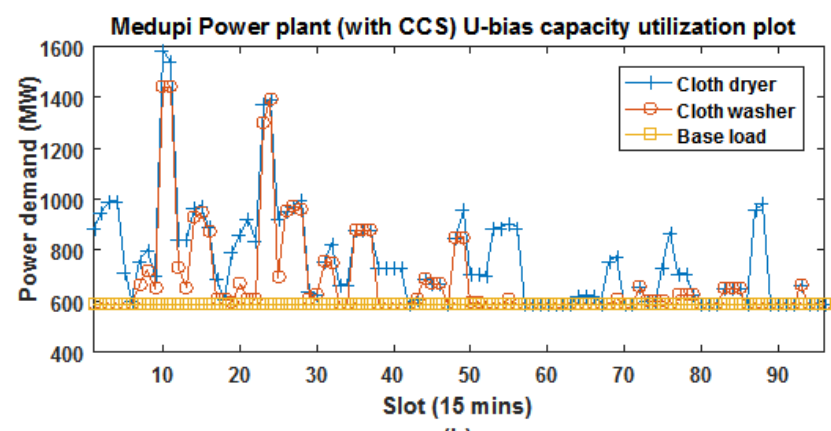

(b)

Figure 3: $100 \%$ household participation power dispatch for $C_{\text {bias }}^{\text {cost }}$ and $U_{\text {bias }}^{\text {cost }}$ options.

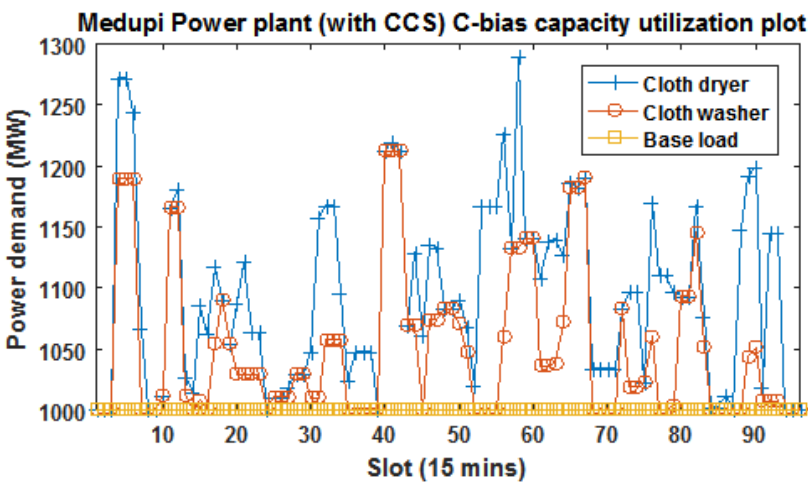

(a)

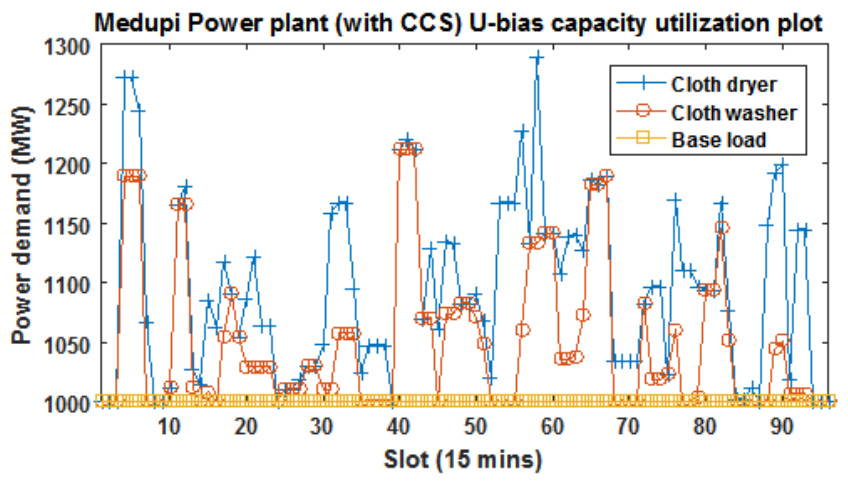

(b)

Figure 4: $50 \%$ household participation power dispatch for $C_{\text {bias }}^{\text {cost }}$ and $U_{\text {bias }}^{\text {cost }}$ options. 


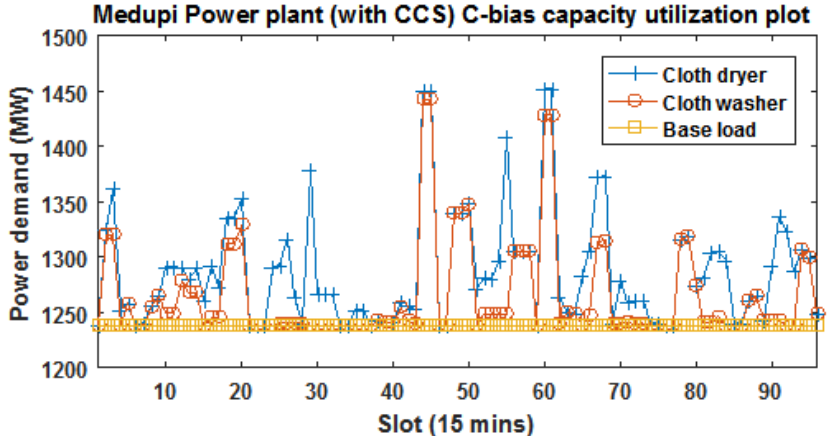

(a)

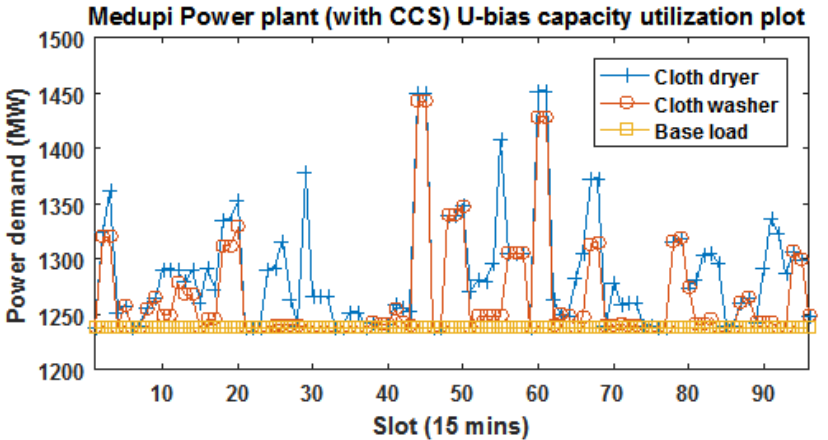

(b)

Figure 5: $30 \%$ household participation power dispatch for $C_{\text {bias }}^{\text {cost }}$ and $U_{\text {bias }}^{\text {cost }}$ options. 